\title{
Evolução dos fluidos mineralizantes e modelo genético dos veios de quartzo auríferos em zona de cisalhamento do depósito Ouro Roxo, Província Tapajós, Jacareacanga (PA), Brasil
}

\author{
Ore fluid evolution and genetic model of gold-bearing quartz veins in shear \\ zone of the Ouro Roxo deposit, Tapajós Province, Jacareacanga (PA), Brazil
}

\author{
Ângela Suélem Rocha Veloso ${ }^{1}$, Márcio Dias Santos ${ }^{1 *}$, Francisco Javier Rios ${ }^{2}$
}

\begin{abstract}
RESUMO: O depósito aurífero Ouro Roxo, localizado no município de Jacareacanga, Província Aurífera do Tapajós, sudoeste do Pará, formou-se em um sistema hidrotermal que gerou veios de quartzo sulfetados, em zona de cisalhamento N-S, dúctil-rúptil, oblíqua, denominada Ouro Roxo-Canta Galo, cortando granitoides calcioalcalinos da Suíte Intrusiva Tropas, de idade paleoproterozoica e hospedeira da mineralização, em rochas localmente milonitizadas. Três tipos de fluidos foram caracterizados como geradores do depósito: 1) fluido aquoso $\mathrm{H}_{2} \mathrm{O}$ $\mathrm{NaCl}-\mathrm{MgCl}_{2}-\mathrm{FeCl}_{2}$ de salinidade baixa a moderada, com temperatura de homogeneização total $\left.(\mathrm{Th})=180-280^{\circ} \mathrm{C} ; 2\right)$ salmoura $\mathrm{H}_{2} \mathrm{O}-\mathrm{NaCl}-$ $\mathrm{CaCl}_{2}$ com $\mathrm{Th}=270-400^{\circ} \mathrm{C}$, provavelmente portadoras de $\mathrm{Cu}$ e $\mathrm{Bi}$, relacionadas geneticamente a um evento magmático contemporâneo ao cisalhamento que sofreu diluição pela mistura com água meteórica, baixando sua salinidade e temperatura $\left(T h=120-380^{\circ} \mathrm{C}\right)$; 3) fluido aquocarbônico de média salinidade, $c o m \mathrm{Th}=230-430^{\circ} \mathrm{C}$, que foi interpretado como o fluido mineralizante mais primitivo, provavelmente aurífero, relacionado com o cisalhamento. As condiçôes de temperatura e pressão (T-P) de formação do minério, estimadas conjuntamente pelo geotermômetro da clorita e as isócoras das inclusôes fluidas, situam-se entre 315 e $388^{\circ} \mathrm{C}$ e 2 a 4,1kb. Dois mecanismos simultâneos provocaram a deposição do minério em sítios de transtensão da zona de cisalhamento: 1) mistura de fluido aquocarbônico com salmoura magmática com aumento de $\mathrm{fO} 2$ e redução de $\mathrm{pH}$; 2) interação entre os fluidos e os feldspatos e minerais ferromagnesianos do granitoide hospedeiro, com reações de hidrólise e sulfetação, provocaram redução de fO2 e fS2, com precipitação de sulfetos de Fe juntamente com ouro. O ambiente orogênico, o estilo filoneano do depósito, o controle estrutural pela zona de cisalhamento, a alteração hidrotermal (propilítica + fílica + carbonataçâa), a associação metálica $(\mathrm{Au}+\mathrm{Cu}+\mathrm{Bi})$, o fluido mineralizante aquocarbônico associado com salmoura magmática na deposição do minério são compatíveis com um modelo orogênico com participaçâo magmática para a gênese do depósito Ouro Roxo.
\end{abstract}

PALAVRAS-CHAVE: Província Tapajós; cisalhamento; inclusões fluidas; Ouro Roxo.

\begin{abstract}
The Ouro Roxo gold deposit, located near Jacareacanga, Tapajós Gold Province, southwestern Para, Brazil, comprises a hydrothermal system of sulfide quartz veins that was hosted by the calc-alkaline mylonite granitoid Tropas Intrusive Suite of Paleoproterozoic age and controlled by the N-S trending ductile-brittle oblique Ouro Roxo-Canta Galo, crosscutting the granitoid Tropas. Three kinds of fluids were identified as sources of mineralization in the Ouro Roxo deposit: 1) an aqueous fluid within the $\mathrm{H}_{2} \mathrm{O}-\mathrm{Na}$ $\mathrm{Cl}-\mathrm{MgCl}_{2}-\mathrm{FeCl}_{2}$ system, with low-to-middle salinity and homogenization temperature $(\mathrm{Th})=180-280^{\circ} \mathrm{C}$; 2) $\mathrm{Cu}$ and Bi-bearing $\mathrm{H}_{2} \mathrm{O}-\mathrm{NaCl}-\mathrm{CaCl}$ brines, with $\mathrm{Th}=270-400^{\circ} \mathrm{C}$, genetically related to a magmatic event coeval to shearing, which underwent dilution by mixing with meteoric water; 3) gold bearing middle-salinity aquocarbonic fluid, with $\mathrm{Th}=230-430^{\circ} \mathrm{C}$, which was interpreted as ore fluid related to shearing. The T-P conditions of ore formation, estimated by chlorite geothermometer and fluid inclusion isochors, range from 315 to $388^{\circ} \mathrm{C}$ and 2,0 to $4,1 \mathrm{~kb}$. The two main mechanisms for gold deposition in transtensional sites of the shear zone were: 1) Mixing of aquocarbonic fluid and magmatic brines induced an increasing of fO2 and decrease of $\mathrm{pH}$; 2) interaction between fluids and feldspars and ferromagnesian minerals of the hoster granitoid which reduced fO2 and fS2 during hydrolysis and sulfidation reactions, with precipitation of iron sulfides together with gold. The orogenic environment, the veining style, the structural control by shearing, the hydrothermal alteration (propylitic+philic+carbonatization), the metallic association $(A u+C u+B i)$, the association of aquocarbonic ore fluid with magmatic brines in ore deposition, are all consistent with an orogenic model for genesis of the Ouro Roxo deposit with magmatic participation.
\end{abstract}

KEYWORDS: Tapajós Province; shearing; fluid inclusions; Ouro Roxo; Quartz-vein gold; Orogenic.

\footnotetext{
${ }^{1}$ Programa de Pós-Graduação em Geologia e Geoquímica, Instituto de Geociências, Universidade Federal do Pará - UFPA, Belém (PA), Brasil. E-mail: angelasveloso@yahoo.com.br,mds@ufpa.br

${ }^{2}$ Centro de Desenvolvimento de Tecnologia Nuclear, Instituto de Geociências, Universidade Federal de Minas Gerais - UFMG, Belo Horizonte (MG), Brasil. E-mail: javier@cdtn.br

*Autor correspondente
}

Manuscrito ID 29887. Recebido em: 18/01/2013. Aprovado em: 03/09/2013. 


\section{INTRODUÇÃO}

A Província Aurífera do Tapajós (PAT), entre os municípios de Jacareacanga, Itaituba, Novo Progresso e Castelo dos Sonhos, sudoeste do Estado do Pará, é uma das mais importantes províncias auríferas do Brasil que, nas três últimas décadas do século passado, viveu seu período áureo com a explotação de sua reserva secundária por meio da atividade garimpeira. Com a exaustáo dos depósitos residuais, a partir dos anos 1990, a Província Tapajós iniciou um novo ciclo de exploração e explotação voltado para os depósitos primários por meio de mineração empresarial que, devido à magnitude de sua reserva secundária, despertou no setor mineral expectativas alvissareiras, não confirmadas até o momento.

O depósito Ouro Roxo, objeto do presente trabalho, é um dos mais importantes depósitos auríferos da PAT, localizado no município de Jacareacanga, região das Vilas São José e Porto Rico, às margens do rio Pacu, na parte centro-oeste da PAT (Fig. 1). A exploração garimpeira no depósito Ouro Roxo data do início dos anos 1980, mas foi somente no início dos anos 1990 que começaram os trabalhos de exploração mineral pela Rio Tinto Desenvolvimentos Minerais (RTDM). No final da década de 1990, a New Bullet Group Inc. adquiriu a concessão da área Ouro Roxo, a qual foi renegociada em 2004 para a Amerix Precious Metals Corporation. Em 2009, a Amerix repassou os direitos minerários do alvo Ouro Roxo para a Amazon Mineral Explorers. O estudo do depósito Ouro Roxo teve como objetivo a caracterização do sistema de fluidos que participou do processo mineralizante para, juntamente com os dados geológicos, petrográficos, mineralógicos e estruturais apresentados por Veloso e Santos (2013, p. 22-36), propor um modelo genético consistente para o mesmo.
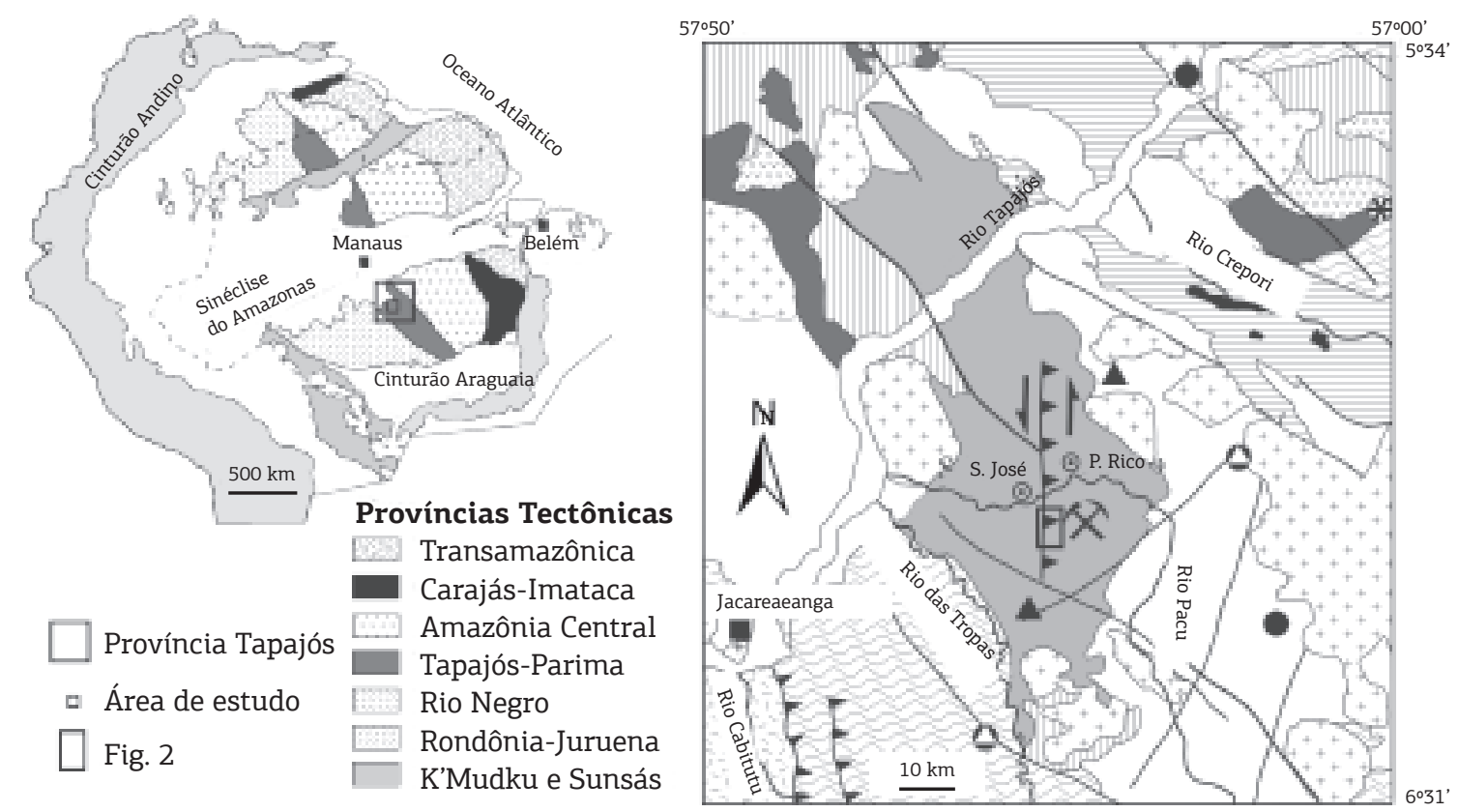

\section{Paleoproterozóico}

Diabásio Creporí ( 1,78 Ga)

Form. Buiuçu: sedimentos terrígenos (1,87 - 1,79 Ga)

Suíte Int. Maloquinha: granitoides $(1,88-1,86 \mathrm{Ga})$

Formação Salustiano: riolitos $(1,88$ - 1,87 Ga)

W.W. Formação Bom Jardim: andesitos

Suíte Intrusiva Ingarana $(\sim 1,88 \mathrm{Ga})$

Suíte Intrusiva Parauarí: granitoides $(1,90$ - 1,88 Ga)

Suíte Intrusiva Tropas: granitoides (1,91 - 1,89 Ga)

Complexo Cuiú-Cuiú: granito-gnaisses $(2,04-2,0 \mathrm{Ga})$

Gr. Jacareacanga: vulcano-sedimentar $(2,1-2,0 \mathrm{Ga})$
Falhas/Zonas de cisalhamento

Falha de empurrão

A Depósitos orogênicos filonianos

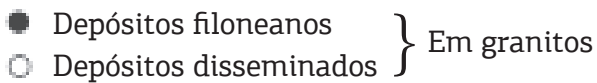

* Depósitos epitermais

- Depósito aurífero não classificado

X Depósito aurífero Ouro Roxo

- Cidade

$\odot$ Vila

Figura 1. Mapa geológico da porção centro-oeste da Província Tapajós, mostrando a área estudada e sua posição na faixa orogênica Tapajós-Parima e no Cráton Amazônico. Adaptado de Almeida et al. (2000), Bahia e Quadros (2000), Ferreira et al. (2000), Klein e Vasquez (2000), Vasquez e Klein (2000) e Santos et al. (2006). 


\section{GEOLOGIA DO DEPÓSITO OURO ROXO}

Os corpos mineralizados do depósito Ouro Roxo, nas proximidades das vilas São José e Porto Rico, na parte centro-oeste da PAT, estão hospedados em uma alternância de milonitos e brechas hidrotermalmente alteradas, descrita em Veloso (2011) e Veloso \& Santos (2013). Os protólitos destas rochas são granitóides cálcio-alcalinos de composição granodiorítica a tonalítica da Suíte Intrusiva Tropas (Santos et al. 2002, 2004), de idade orosiriana, que foram afetados por uma zona de cisalhamento dúctil-rúptil oblíqua, de direção N-S, denominada Ouro Roxo-Cantagalo (ZCOC), visualizada na figura 2, e que enquadra-se no terceiro evento de deformação (D3) da PAT (Klein \& Vasquez, 2000).
O depósito Ouro Roxo é constituído por enxame de veios de quartzo sulfetados e, ocasionalmente, também por pods de quartzo mineralizados, controlados estruturalmente pela zona de cisalhamento Ouro RoxoCanta Galo. Os veios e pods mineralizados estão sempre envolvidos por um halo de alteraçáo hidrotermal bem desenvolvido e constituído principalmente por fengita + clorita + carbonato + sulfeto (pirita) e minerais-minério disseminados. Os veios e charutos, juntamente com seus halos de alteração, formam corpos mineralizados alojados normalmente ao longo da direção principal do cisalhamento (N-S), descritos em Veloso (2001) e Veloso \& Santos (2013).

O quartzo é o principal mineral da ganga. Sete geraçóes deste mineral foram descritas em Veloso (2011) e Veloso \& Santos (2013), das quais cinco são hidrotermais

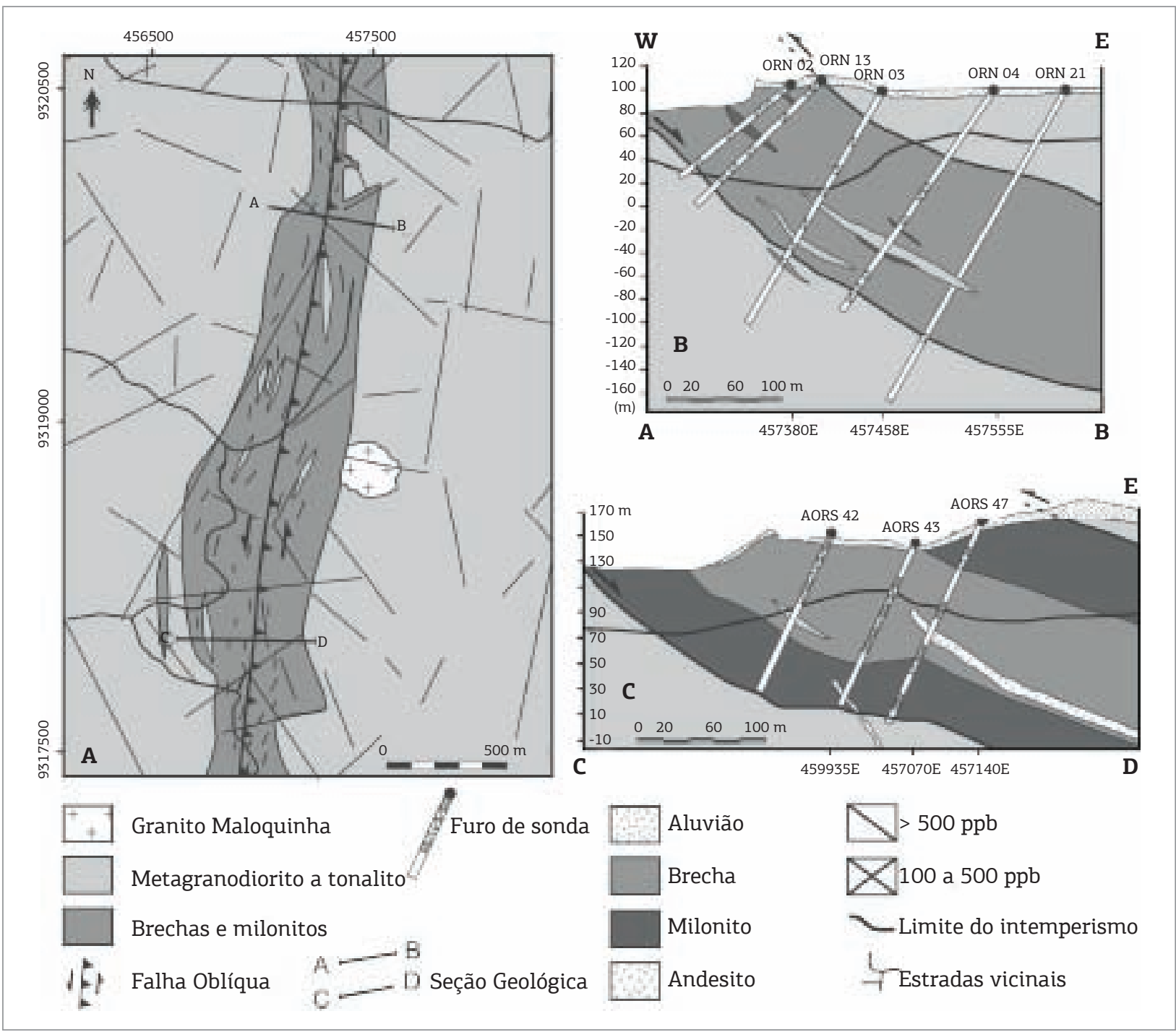

Figura 2. Mapa geológico da região do depósito Ouro Roxo e a zona de cisalhamento Ouro Roxo-Canta Galo em (A), e duas seções geológicas, uma no Ouro Roxo Norte (B) e outra no Ouro Roxo Sul (C), modificado de Souza (2007). 
(quartzo3 a 7) que foram precedidas por duas gerações precoces, a primeira representada por cristais estirados contemporâneos com cristais também estirados de pirita1, ambos interpretados como fases magmáticas pré-mineralização afetadas pelo cisalhamento (Fig. 3). A segunda geração de quartzo é metamórfica e ocorre como cristais microcristalinos nas sombras de pressão dos milonitos. A mineralização está relacionada às duas primeiras geraçóes de quartzo hidrotermal (quartzo3 e 4), associados com cristais anédricos de pirita2, calcopirita1, ouro, bismutinita e bismuto nativo (Fig. 4). A segunda geração de calcopirita substitui as bordas de cristais de pirita2 (Fig. 5) e a terceira geração de pirita é representada por cristais euédricos pós-mineralização que ocorrem em vênulas tardias. As três últimas geraçôes de quartzo hidrotermal (Quartzo5, 6 e 7) são pósmineralização e não estão associados com sulfetos, a não ser as vênulas com pirita3 contemporâneas às vênulas com quartzo7 microcristalino que cortam o minério e as geraçôes anteriores de quartzo. Os estudos microtermométricos foram realizados nos quartzos3, 4 e 6.

A figura 4 mostra a sequência paragenética das fases hidrotermais do depósitos Ouro Roxo, com as cinco geraçóes de quartzo (q3, q4, q5, q6 e q7), destacando as duas gerações relacionadas com a mineralização aurífera (q3 e q4). Nessa figura, são mostradas também as fases minerais metamórficas pré-mineralização, associadas com qartzo2 e as fases minerais pós-mineralização (vênulas tardas), associadas com quartzo7.

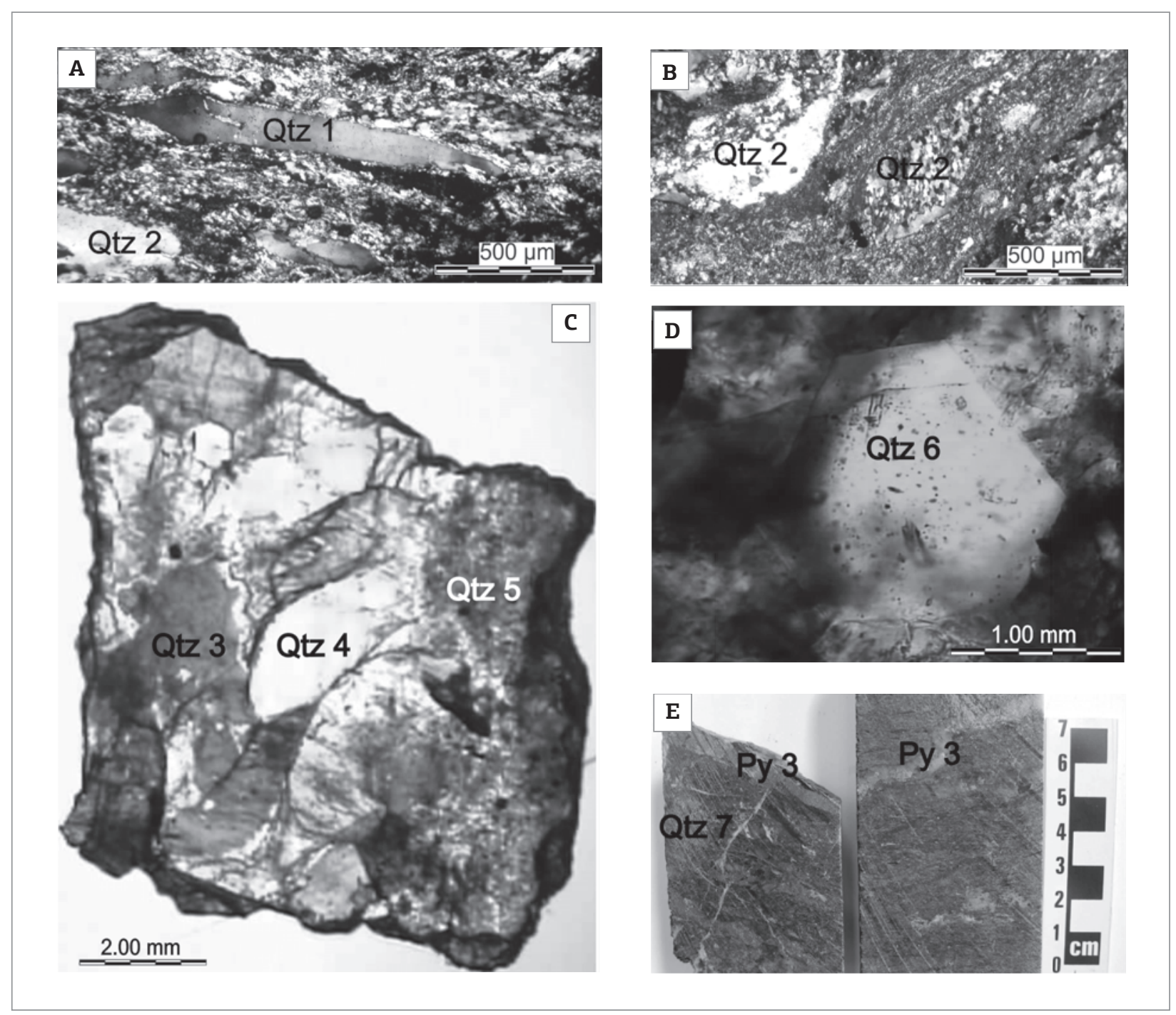

Figura 3. Gerações de quartzo do depósito Ouro Roxo. (A) Quartzol estirado, primeira geração (magmática). (B) Quartzo2 microcristalino, segunda geração (metamórfica) em sombras de pressão ao longo de foliação milonítica. (C) Quartzo3 anédrico com bordas corroídas, primeira geração hidrotermal; quartzo4 subédrico com agulhas de turmalina, segunda geração hidrotermal; quartzo5 microcristalino, terceira geração hidrotermal. (D) Quartzo6 euédrico com agulhas de turmalina, quarta geração hidrotermal. (E) Quartzo7, vênulas tardias que cortam o minério sulfetado, quinta geração hidrotermal. 


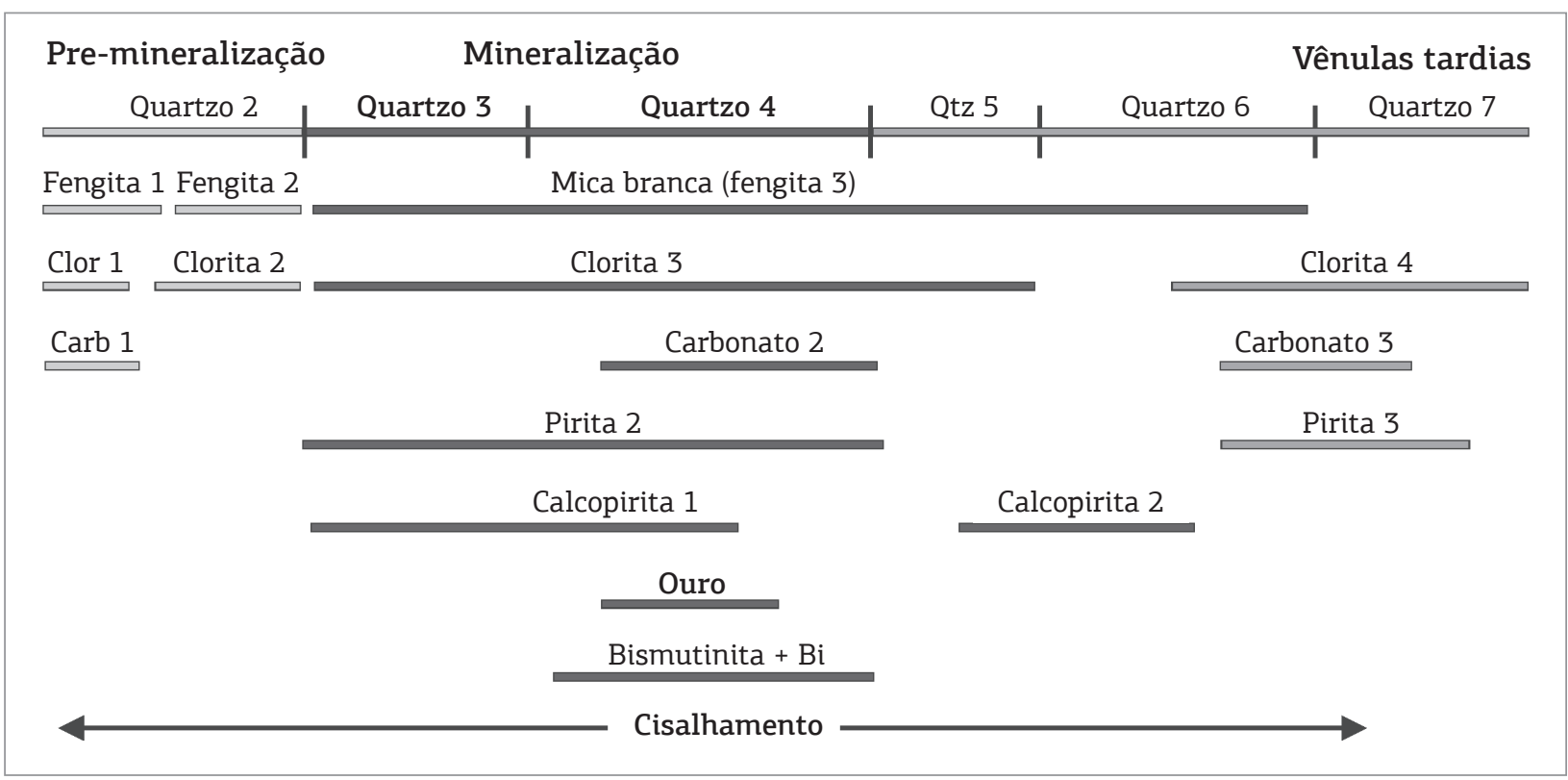

Figura 4. Sequência paragenética das fases hidrotermais do depósito Ouro Roxo, mostrando as cinco gerações hidrotermais de quartzo (q3, q4, q5, q6 e q7), com destaque para as duas gerações (q3 e q4) associadas com a mineralização aurífera (barra escura). Fases pré-mineralização, associadas com quartzo2 (barra clara). Fases pósmineralização, associadas com q5, q6 e q7 (barra cinza média).
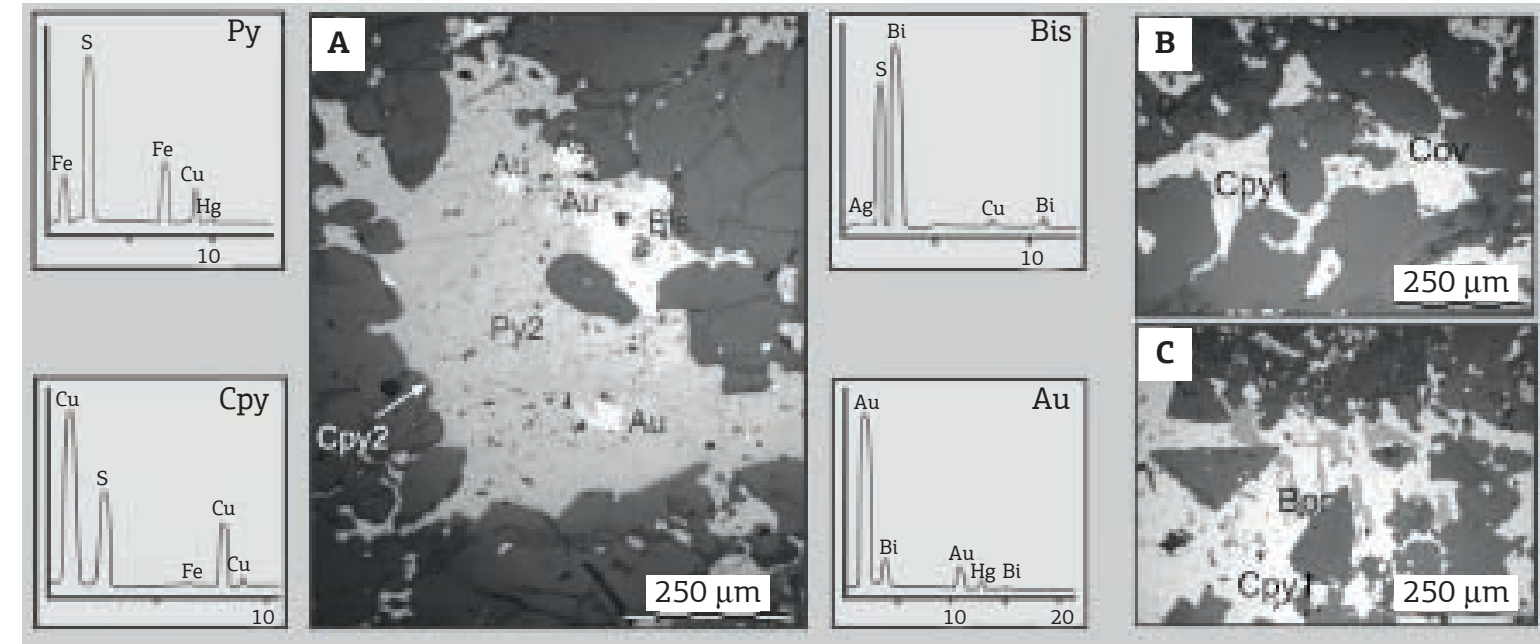

Figura 5. Cristal de pirita2 substituído nas bordas por calcopirita2 e com inclusões de ouro associado com bismutinita e bismuto nativo (A). Calcopirital substituída por covelita (B) e por bornita (C).

\section{MATERIAIS E MÉTODOS}

O sistema de fluidos geradores do depósito Ouro Roxo foi investigado por meio do estudo das inclusóes fluidas observadas ao microscópio em lâminas bipolidas de cristais de quartzo dos veios mineralizados. As inclusóes foram petrograficamente descritas e classificadas e, posteriormente, submetidas a mediçóes microtermométricas no laboratório de Metalogênese do Instituto de Geociências da Universidade Federal do Pará (UFPA) e no laboratório de microtermometria do Centro de Desenvolvimento de Tecnologia Nuclear (CDTN) da Universidade Federal de Minas
Gerais (UFMG), utilizando nos dois laboratórios uma platina Linkam THMSG600 acoplada a um microscópio petrográfico. Para calibrações foram utilizadas inclusões fluidas sintéticas de Bubbles INC, blacksburg, VA, USA $\left(\mathrm{H}_{2} \mathrm{O}\right.$, critical density, $\mathrm{H}_{2} \mathrm{O}$ $+\mathrm{CO}_{2}-10$ mole $\% \mathrm{CO}_{2}, \mathrm{H}_{2} \mathrm{O}-\mathrm{NaCl} 10$ e 25 wt $\% \mathrm{NaCl}$ ).

Os ensaios microtermométricos nos dois laboratórios citados permitiram a determinação da densidade e salinidade das inclusôes fluidas e das temperaturas do ponto eutético (Te), da fusão do gelo (Tfgelo), da fusão do $\mathrm{CO}_{2}\left(\mathrm{TfCO}_{2}\right)$, da fusão do clatrato (Tfclat), da dissolução da halita (TDH), de homogeneização do $\mathrm{CO}_{2}\left(\mathrm{ThCO}_{2}\right)$ e de homogeneização total (Th) das inclusóes. 
As condições de temperatura e pressão de formação do depósito Ouro Roxo foram estimadas com base nos dados microtermométricos e complementados com um geotermômetro independente. As temperaturas foram baseadas na proporção catiônica do alumínio tetraédrico da clorita $\left(\mathrm{A}^{\mathrm{IV}}\right)$, que permite calcular a temperatura de cristalização por meio da equação $\mathrm{T}=321,98 \mathrm{Al}^{\mathrm{IV}}-61,92$, conforme estabelecido por Cathelineau \& Neiva (1985) e Cathelineau (1988). Para tanto, 21 microanálises de clorita em lâminas polidas e previamente metalizadas com carbono foram realizadas no laboratório de microssonda eletrônica do Instituto de Geociências da Universidade de São Paulo (USP) em uma microssonda Jeol JXA-8600, cujas condições operacionais usadas nas análises de WDS foram: tensão de aceleração $15 \mathrm{Kv}$, corrente de feixe $5 \mu \mathrm{m}$ e tempo de contagem do feixe de $10 \mathrm{~s}$. Os valores da pressão do fluido hidrotermal do depósito foram obtidas a partir das isócoras das inclusóes fluidas e calculadas com o auxílio do programa MacFlincor 1.4.

\section{PETROGRAFIA E MICROTERMOMETRIA DAS INCLUSÕES FLUIDAS}

Os estudos microtermométricos dos fluidos mineralizantes do depósito Ouro Roxo foram realizados em cristais de quartzo de veios mineralizados encaixados em milonitos na direção principal (N-S) do cisalhamento e amostrados ao longo dos furos de sondagem do depósito. Os melhores candidatos a representar o(s) fluido(s) mineralizante(s) do depósito Ouro Roxo são inclusôes fluidas (IF) primárias e pseudosecundárias bem preservadas em cristais de quartzo das geraçóes 3 e 4 . As massas microcristalinas do quartzo5 contêm inclusôes, porém o tamanho muito reduzido das IF inviabilizou a obtenção de medidas microtermométricas nestes cristais. As IF salinas do quartzo6 foram estudadas, porém descartadas como possíveis representantes do fluido mineralizante por ser esta geração posterior a mineralização e por apresentar predomínio de IF secundárias. Os quartzos 1 e 2 também não foram estudadas microtermometricamente, uma vez que estas duas geraçôes de quartzo são anteriores a mineralização. Petrograficamente, foram identificados três tipos de inclusóes fluidas nas geraçóes q3 e q4 de quartzo, quando observadas a temperatura ambiente: 1) IF aquosas não saturadas, normalmente bifásicas $\left(\mathrm{H}_{2}\right.$ Olíquida + $\mathrm{H}_{2}$ Ovapor); 2) IF aquosas saturadas trifásica ou polifásica $\left(\mathrm{H}_{2}\right.$ Olíquida $+\mathrm{H} 2$ Ovapor +1 ou mais cristais de saturação); 3) IF aquocarbônicas bi ou trifásica $\left(\mathrm{H}_{2}\right.$ Olíquida + $\mathrm{CO}_{2}$ líquido $+\mathrm{CO}_{2}$ vapor, nem sempre presente em temperatura ambiente).
A salinidade das IF aquosas não saturadas foi calculada pela equação de Bodnar (1993) a qual utiliza a temperatura de fusão do gelo (Tfgelo) para o cálculo da salinidade no sistema $\mathrm{H}_{2} \mathrm{O}-\mathrm{NaCl}$, enquanto que para as IF aquosas saturadas foi utilizada a equação de Sterner et al. (1988), a qual utiliza a temperatura de fusão da halita $(\mathrm{TDH})$ e/ou silvita (TDS) para o cálculo da salinidade no sistema $\mathrm{H}_{2} \mathrm{O}-\mathrm{NaCl}$ $\mathrm{KCl}$. As duas equaçóes podem ser utilizadas também para outros sistemas sendo, porém, a salinidade calculada em $\%$ peso equivalente de $\mathrm{NaCl}$. A salinidade das IF aquocarbônicas foi calculada pela equação de Bozo et al. 1973 (in Parry, 1973). A densidade (d) dos fluidos contidos nas IF foi calculada com o auxílio do programa McFlincor, versão 1.4 (Brown \& Lamb, 1989), utilizando-se, para as IF aquosas, as Tfgelo e Th (IF não saturadas) e Tfgelo e TDH (IF saturadas) e, para as IF aquocarbônicas, foram utilizadas as $\mathrm{ThCO}_{2}$ e a porcentagem volumétrica da fase aquosa (grau de preenchimento F) e da fase carbônica (VG).

\section{Inclusões aquosas não saturadas}

As inclusôes fluidas aquosas não saturadas ocorrem como IF bifásicas $(\mathrm{L}+\mathrm{V})$ subarredondadas ou alongadas, primárias, pseudosecundárias e secundárias. As IF primárias ocorrem de maneira isolada no interior dos cristais de quartzo3 (Fig. 6A), com grau de preenchimento $(\mathrm{F})$ entre 0,85 e 0,8 e tamanhos entre 10 e $20 \mu \mathrm{m}$. As IF pseudosecundárias ocorrem alinhadas em fraturas cicatrizadas em quartzo3 e 4 (Figs. 6B e D), com F entre 0,85 e 0,7 e tamanhos inferiores a $5 \mu \mathrm{m}$, o que torna sua observação uma tarefa difícil. As IF secundárias ocorrem em trilhas retilíneas, comumente agrupadas em feixes que atravessam os limites dos cristais de quartzo 3 e 6 , com $\mathrm{F}$ entre 0,8 e 0,85 e tamanhos diminutos, entre 5 e $8 \mu \mathrm{m}$ (Figs. $6 \mathrm{C}$ e E). As temperaturas do ponto eutético (Te) das IF aquosas não saturadas situaram-se em dois intervalos distintos, entre -34 e $-43^{\circ} \mathrm{C}$ em quartzo 3 e entre -58 e $-66^{\circ} \mathrm{C}$ em quartzo 4 e 6, compatíveis, segundo Borizenco (1977), respectivamente, com os sistemas $\mathrm{H}_{2} \mathrm{O}-\mathrm{NaCl}-\mathrm{MgCl}_{2}-\mathrm{FeCl}_{2}$ e $\mathrm{H}_{2} \mathrm{O}-\mathrm{NaCl}-\mathrm{CaCl}_{2}$ (Fig. 7A). A tabela 1 exibe todos os parâmetros microtermométricos obtidos para as IF aquosas não saturadas, cujas frequências são visualizadas na figura 7 .

\section{Inclusões aquosas saturadas}

Ocorrem como IF trifásicas $(\mathrm{L}+\mathrm{V}+\mathrm{S})$ e mais raramente polifásicas, subarredondadas a ligeiramente alongadas, pseudosecundárias (em quartzo4) e primárias (em quartzo6), com F entre 0,5 e 0,65 e tamanhos entre 4 e $10 \mu \mathrm{m}$ (Figs. 8A e B). As IF trifásicas contêm somente um cristal de saturação euédrico (cúbico) compatível com haletos, provavelmente halita, enquanto que as IF polifásicas podem conter até três fases sólidas $(\mathrm{L}+\mathrm{V}+\mathrm{S} 1+\mathrm{S} 2+\mathrm{S} 3)$, sendo os cristais euédricos (cúbicos) provavelmente halita, 

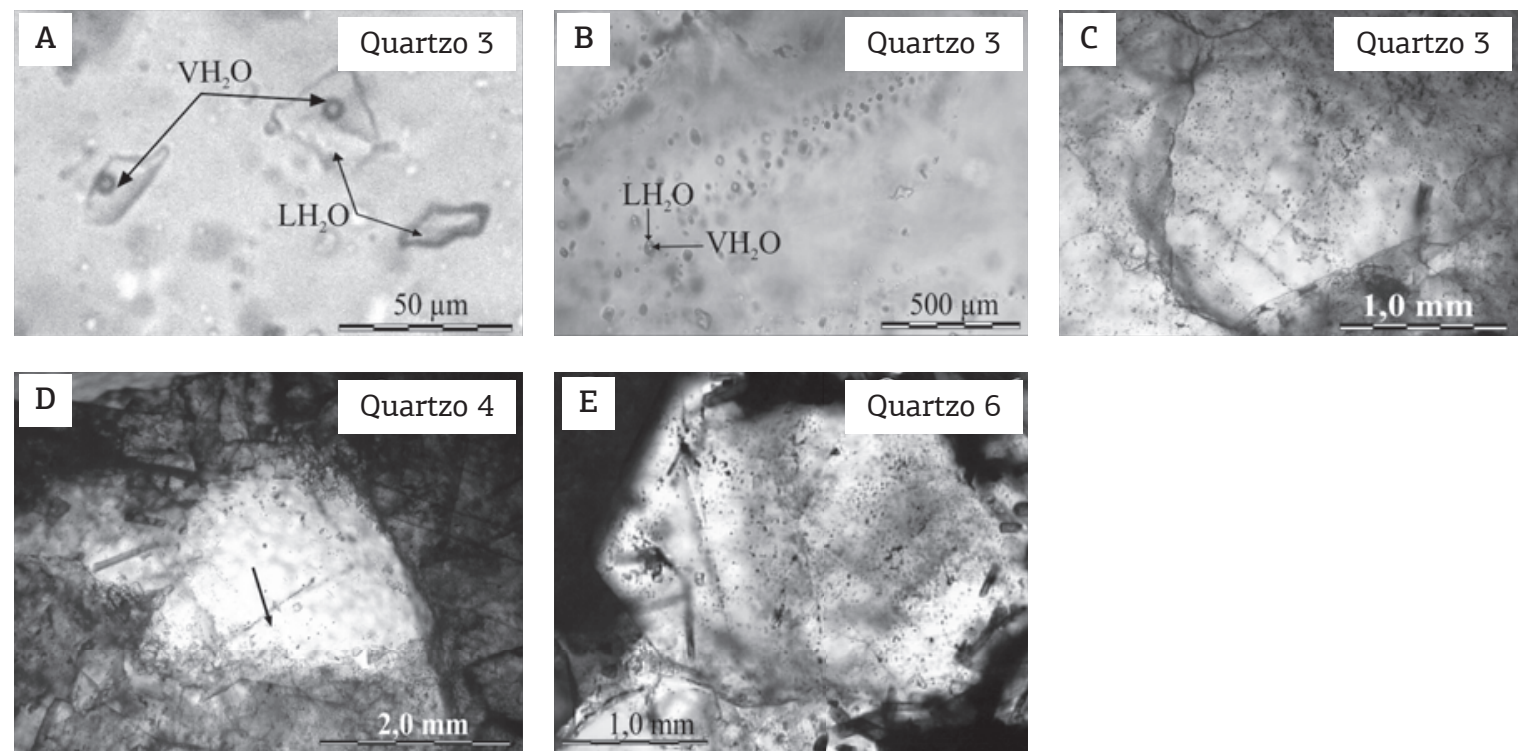

Figura 6. Fotomicrografias de inclusões fluidas (IF) aquosas não saturadas bifásicas em veios mineralizados do depósito Ouro Roxo. (A) IF primárias; (B e D) IF pseudossecundárias; (C e E) IF secundárias.

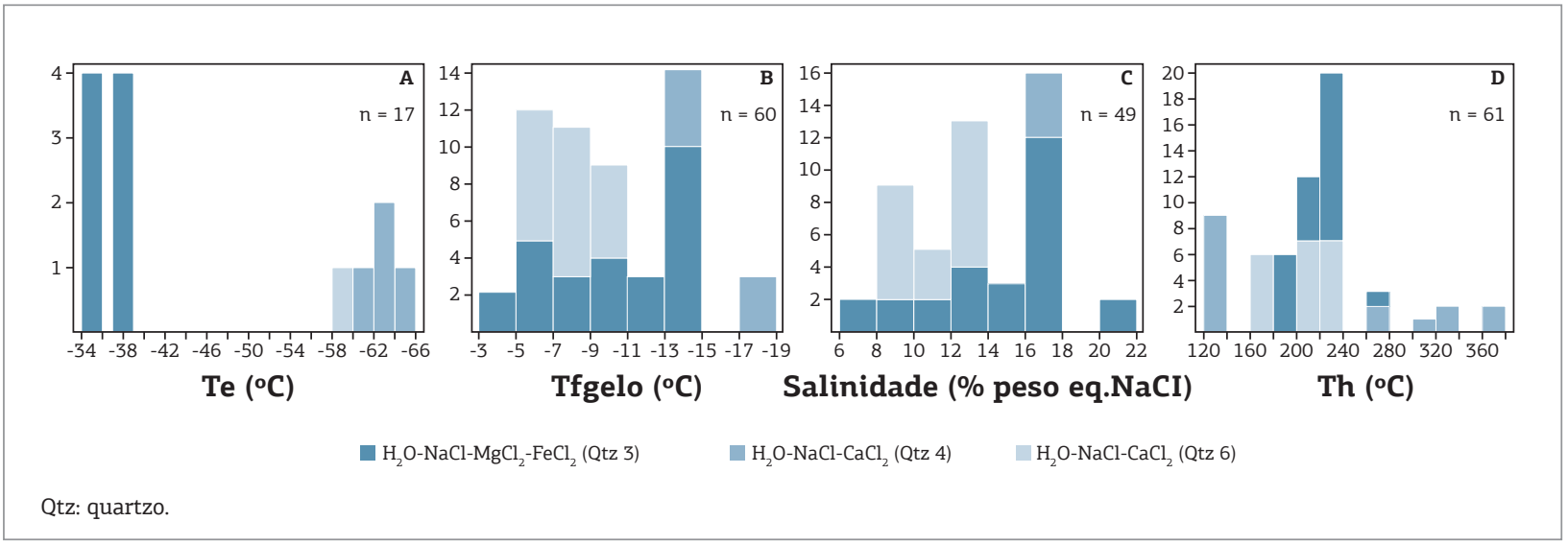

Figura 7. Histograma de frequência referente às inclusões fluidas (IF) aquosas não saturadas em quartzo das gerações 3,4 e 6 do depósito Ouro Roxo. (A) Ponto eutético (Te); (B) fusão do gelo (Tfgelo); (C) salinidade; (D) temperatura de homogeneização (Th).

e os cristais subédricos, com formas mais arredondadas e alongadas, possivelmente silvita (Figs. 8A e B).

As temperaturas do ponto eutético ( $\mathrm{Te}$ ) foram difíceis de serem obtidas, porém quando observadas variaram entre -60 a $-66^{\circ} \mathrm{C}$ (tabela 2 e figura $8 \mathrm{c}$ ), compatíveis com o sistema $\mathrm{H}_{2} \mathrm{O}-\mathrm{NaCl}-\mathrm{CaCl}_{2}$ (Davis et al. 1990, Fig. 9C). Segundo esses autores, valores anômalos, inferiores a $-60^{\circ} \mathrm{C}$ (Tabela 2), podem ser relacionados a fenômenos de metaestabilidade do sistema $\mathrm{H}_{2} \mathrm{O}-\mathrm{NaCl}-\mathrm{CaCl}_{2}$ ou presença de cátions incomuns (por exemplo, $\mathrm{Li}$ e $\mathrm{Sr}$ ), ou ainda transiçôes de fases do gelo hexagonal em fluidos de idêntica composição (Walker \& Samson 1998). A provável presença de cristais de silvita $(\mathrm{KCl})$ e a ocorrência de mica branca na paragênese hidrotermal indicam que o potássio pode ser um componente importante do fluido aquoso saturado e possivelmente do não saturado também. A tabela 2 exibe todos os parâmetros microtermométricos obtidos para as IF aquosas saturadas. Os cristais de halita fundem antes da temperatura de homogeneização total (Th) das IF que ocorre sempre no estado líquido (tabela 2). As frequências das Th são visualizadas na figura $8 \mathrm{D}$.

A composição das IF aquosas saturadas, expressa pelos conteúdos de $\mathrm{NaCl}$ e $\mathrm{CaCl}_{2}$ em \% peso (Tabela 2), foi obtida por meio do esquema proposto por Williams-Jones e Samson (1990) que utiliza as Tfgelo e TDH plotadas no diagrama ternário $\mathrm{H}_{2} \mathrm{O}-\mathrm{NaCl}-\mathrm{CaCl}_{2}$ (Fig. 9). Os valores da Tfgelo são 
Metalogênese do depósito Ouro Roxo (PA), Brasil

Tabela 1. Principais resultados microtermométricos obtidos a partir das inclusões fluidas aquosas não saturadas do depósito Ouro Roxo

\begin{tabular}{|c|c|c|c|}
\hline \multirow{3}{*}{$\begin{array}{l}\text { Parâmetros } \\
\text { Geração/Qtz }\end{array}$} & \multicolumn{3}{|c|}{ Sistema de fluidos aquosos não saturados } \\
\hline & \multicolumn{2}{|c|}{$\mathrm{H}_{2} \mathrm{O}-\mathrm{NaCl}-\mathrm{MgCl}_{2}-\mathrm{FeCl}_{2}$} & \multirow{2}{*}{$\begin{array}{c}\mathrm{H}_{2} \mathrm{O}-\mathrm{NaCl}-\mathrm{CaCl} \\
\text { Quarto } 6\end{array}$} \\
\hline & Quarto 3 & Quarto 4 & \\
\hline $\mathrm{N}^{\circ}$ de IF & 70 & 81 & 90 \\
\hline $\mathrm{F}$ & 0,7 a 0,85 & 0,7 a 0,85 & 0,8 a 0,85 \\
\hline Tipo de IF & $\mathrm{P} / \mathrm{P}-\mathrm{S} / \mathrm{S}$ & P-S & $\mathrm{S}$ \\
\hline $\mathrm{Te}\left({ }^{\circ} \mathrm{C}\right)$ & $-34 a-43$ & \multicolumn{2}{|c|}{$-58 a-66$} \\
\hline Tfgelo $\left({ }^{\circ} \mathrm{C}\right)$ & $-3,1$ a $-15,3$ & $-13 a-18$ & 5 a -11 \\
\hline Densidade $\left(\mathrm{g} / \mathrm{cm}^{3}\right)$ & 0,89 a 1,0 & \multicolumn{2}{|c|}{0,89 a 0,96} \\
\hline $\begin{array}{l}\text { Salinidade } \\
\text { (\% peso equiv. } \mathrm{NaCl} \text { ) }\end{array}$ & 6 a 18 & 16 a 22 & 8 a 14 \\
\hline $\operatorname{Th}\left({ }^{\circ} \mathrm{C}\right)$ & 160 a 270 & 240 e 370 & 100 e 220 \\
\hline
\end{tabular}

Qtz: quartzo; IF: inclusões fluidas; P: primária; P-S: pseudossecundária; S: IF secundária; F: grau de preenchimento Te: ponto eutético; Tfgelo: temperatura de fusão do gelo; Th: temperatura de homogeneização.

Tabela 2. Principais resultados microtermométricos obtidos para as inclusões fluidas aquosas saturadas do depósito Ouro Roxo

\begin{tabular}{|c|c|c|c|c|c|c|c|}
\hline \multirow{3}{*}{$\begin{array}{l}\text { Parâmetros } \\
\text { Geração/Qtz }\end{array}$} & \multicolumn{7}{|c|}{ Fluido aquoso saturado } \\
\hline & \multicolumn{7}{|c|}{$\mathrm{H}_{2} \mathrm{O}-\mathrm{NaCl}-\mathrm{CaCl}_{2}$} \\
\hline & \multicolumn{4}{|c|}{ Quarto 4} & \multicolumn{3}{|c|}{ Quarto 6} \\
\hline $\mathrm{N}^{\circ}$ de IF & \multicolumn{4}{|c|}{36} & \multicolumn{3}{|c|}{15} \\
\hline Tipo de IF & \multicolumn{4}{|c|}{ P-S } & \multicolumn{3}{|c|}{$\mathrm{P}$} \\
\hline $\mathrm{F}$ & \multicolumn{4}{|c|}{0,4 a 0,6} & \multicolumn{3}{|c|}{0,4 a 0,65} \\
\hline $\mathrm{Te}\left({ }^{\circ} \mathrm{C}\right)$ & \multicolumn{4}{|c|}{-60 a $-66^{\circ} \mathrm{C}$ e -74 a -76} & \multicolumn{3}{|c|}{-60 a -64} \\
\hline $\begin{array}{l}\text { Densidade } \\
\left(\mathrm{g} / \mathrm{cm}^{3}\right)\end{array}$ & \multicolumn{4}{|c|}{1,11 a 1,12} & \multicolumn{3}{|c|}{1,13 a 1,14} \\
\hline \multirow[t]{3}{*}{ Th $\left({ }^{\circ} \mathrm{C}\right)$} & \multicolumn{4}{|c|}{260 e 420} & \multicolumn{3}{|c|}{260 e 350} \\
\hline & \multicolumn{4}{|c|}{ Inclusão } & \multicolumn{3}{|c|}{ Inclusão } \\
\hline & 1 & 2 & 3 & 4 & 5 & 6 & 7 \\
\hline Tfgelo $\left({ }^{\circ} \mathrm{C}\right)$ & 32,3 & 35,2 & 33,5 & 39,0 & 31,7 & 33,4 & 28,7 \\
\hline $\mathrm{TDH}\left({ }^{\circ} \mathrm{C}\right)$ & 190,0 & 163,7 & 218,2 & 186,1 & 163,8 & 176,3 & 173,2 \\
\hline $\mathrm{NaCl}$ & 19,5 & 22,0 & 16,0 & 15,0 & 17,0 & 17,5 & 19,5 \\
\hline $\mathrm{CaCl}_{2}$ & 22,0 & 22,0 & 24,5 & 26,0 & 22,0 & 24,5 & 19,5 \\
\hline $\mathrm{NaCl} / \mathrm{CaCl}$ & 0,45 & 1,0 & 0,66 & 0,57 & 0,57 & 0,71 & 1,0 \\
\hline $\begin{array}{l}\text { Salinidade } \\
\text { (\% peso } \\
\text { equiv. } \mathrm{NaCl} \text { ) }\end{array}$ & 31,38 & 30,21 & 32,82 & 31,20 & 30,21 & 30,75 & 30,48 \\
\hline
\end{tabular}

Qtz: quartzo; IF: inclusões fluidas; P-S: pseudossecundária; P: primária; Te: ponto eutético; Th: temperatura de homogeneização; Tfgelo: temperatura de fusão do gelo; TDH: temperatura de dissolução da halita.

plotados sobre a linha cotética entre os campos gelo+líquido e hidrohalita+ líquido e, a partir desses pontos, traça-se uma linha até o ponto de composição da hidrohalita na linha $\mathrm{H}_{2} \mathrm{O}$ $\mathrm{NaCl}$. O cruzamento dessas linhas com as isotermas de TDH definem os pontos que representam as proporçóes percentuais

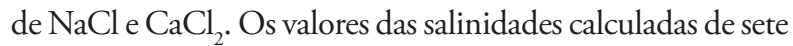

IF (4 do quartzo4 e 3 do quartzo6), pela equação de Sterner et al. (1988), situam-se entre 30,2 e $32,8 \%$ peso equiv. $\mathrm{NaCl}$, especificados na Tabela 2 . As fraçóes molares de halita, $\mathrm{NaCl} /$ $\left(\mathrm{NaCl}+\mathrm{CaCl}_{2}\right)$, normalmente inferiores a 0,5 (Tabela 2), indicam um fluido rico em cálcio, que resultou em expressiva carbonatação das rochas hospedeiras do minério. 

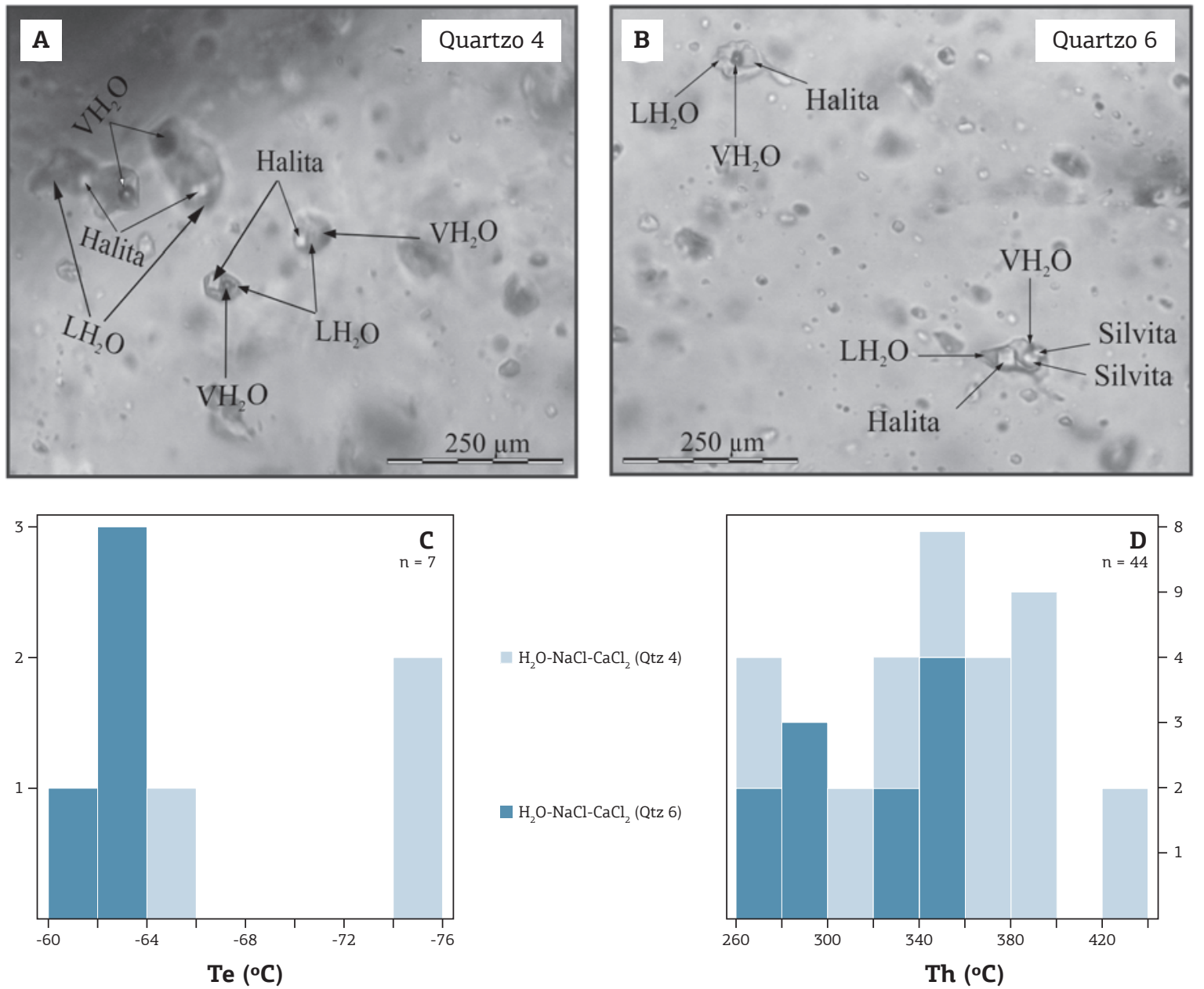

Figura 8. Fotomicrografias de inclusões fluidas (IF) aquosas saturadas em quartzo 4 (A) e quartzo 6 (B). Histograma de frequência referente às IF aquosas saturadas em quartzo4 e 6; (C) temperaturas do ponto eutético (Te); (D) temperatura de homogeneização (Th).

\section{Inclusões aquocarbônicas (sistema $\mathrm{H}_{2} \mathrm{O}-\mathrm{CO}_{2}-\mathrm{NaCl}$ )}

As inclusôes fluidas aquocarbônicas primárias ocorrem em cristais de quartzo das geraçôes 3 e 4 . Foram estudas 128 IF aquocarbônicas (69 em q3 e 59 em q4), as quais ocorrem de maneira aleatória no interior dos cristais de quartzo das duas geraçôes, tanto como IF bifásicas como trifáscas (Fig. 10A e B), com formas irregulares, ligeiramente alongadas, tamanhos entre 6 e $15 \mu \mathrm{m}$ e F quase invariável (em torno de 0,6).

A fase carbônica das IF aquocarbônicas, tanto trifásicas como bifásicas, homogeneíza-se para o $\mathrm{CO}_{2}$ líquido. $\mathrm{A} \mathrm{ThCO}_{2}$ das IF trifásicas foi obtida com um pequeno aquecimento das inclusóes até o desaparecimento do $\mathrm{CO}_{2}$ gasoso entre 24,2 e $31,7^{\circ} \mathrm{C}$. No caso das IF bifásicas, as mesmas foram submetidas a um pequeno resfriamento até aparecer a bolha de $\mathrm{CO}_{2}$ gasoso, após o que, com um pequeno aquecimento, a homogeneização da fase carbônica foi alcançada com $\mathrm{ThCO}_{2}$ entre 25,4 e $29,6^{\circ} \mathrm{C}$. As medidas da temperatura de fusão do $\mathrm{CO}_{2}\left(\mathrm{TfCO}_{2}\right)$ situaram-se entre $-57,9$ e $-56,9^{\circ} \mathrm{C}$ nas duas geraçóes de quartzo (Fig. $11 \mathrm{~A}$ ), mostrando um pequeno abaixamento em relação ao ponto de fusão do $\mathrm{CO}_{2}$ puro $\left(-56,6^{\circ} \mathrm{C}\right)$, o que indica uma participação discreta de outros gases na fase carbônica, provavelmente metano. No diagrama $\mathrm{TfCO}_{2}$ versus $\mathrm{ThCO}_{2}$, a quantidade de metano nas IF aquocarbônicas foi estimada aproximadamente em 4 a $9 \mathrm{~mol} \%$ nas duas geraçóes de quartzo (Fig. 11D).

O ponto eutético (Te) para as IF aquocarbônicas foi de difícil observação e uma única medida obtida de $-36,9^{\circ} \mathrm{C}$, em cristal de quartzo4, pode indicar a possível participação de $\mathrm{FeCl}_{2}$ no fluido. As medidas de fusão do gelo (Tfgelo) situaram-se entre -5 e $-11^{\circ} \mathrm{C}$ nas duas geraçóes de quartzo 


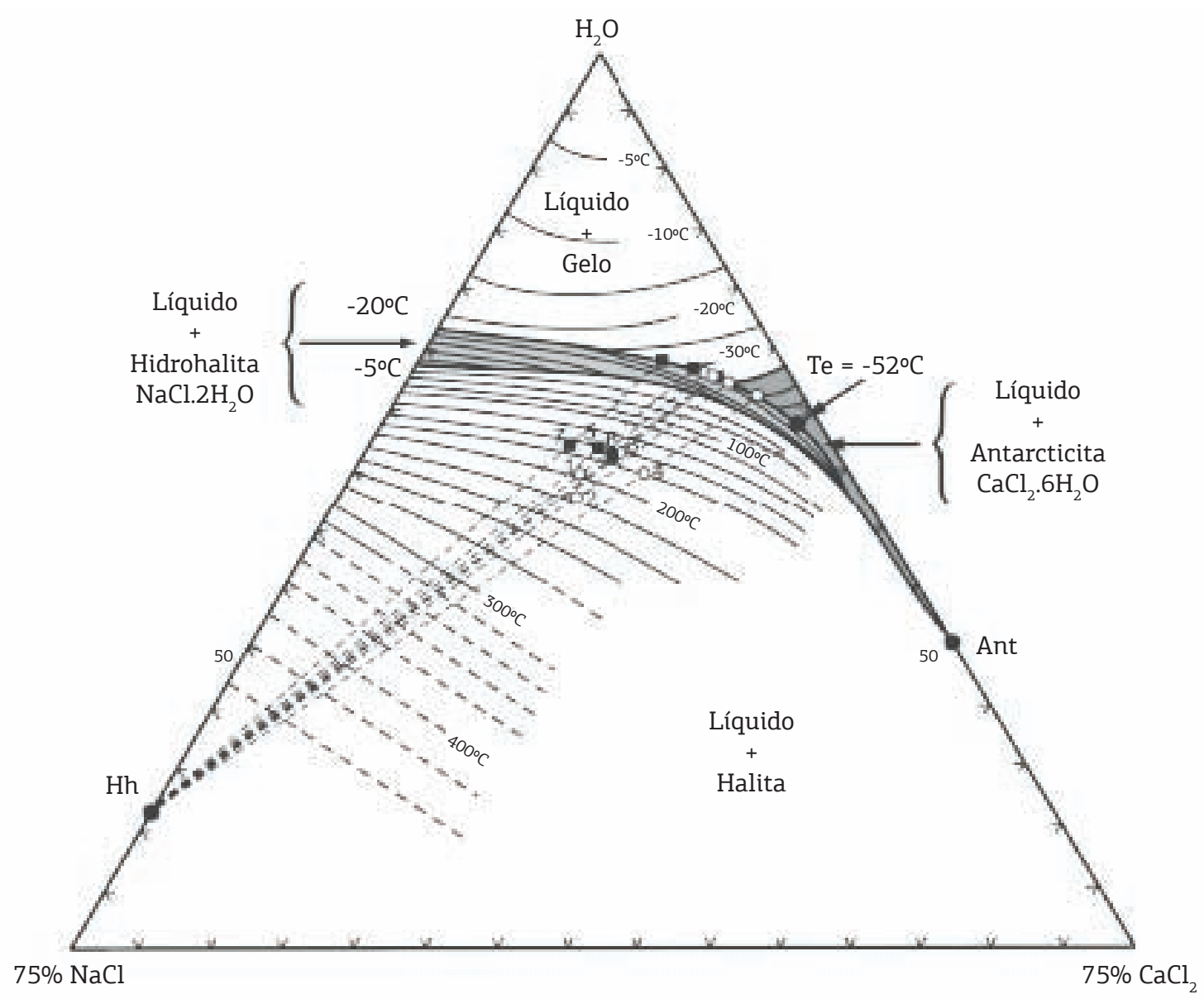

Te: temperaturas do ponto eutético; Hh: hidrohalita; Ant: Antarcticita.

Figura 9. Inclusões fluidas aquosas saturadas saturadas do quartzo4 (círculo) e do quartzo6 (quadrado) plotadas no diagrama $\mathrm{H}_{2} \mathrm{O}-\mathrm{NaCl}-\mathrm{CaCl}_{2}$. Campos e isotermas segundo Williams-Jones 2 Samson (1990). As composições dessas amostras, calculadas a partir do diagrama, estão representadas na Tabela 2.
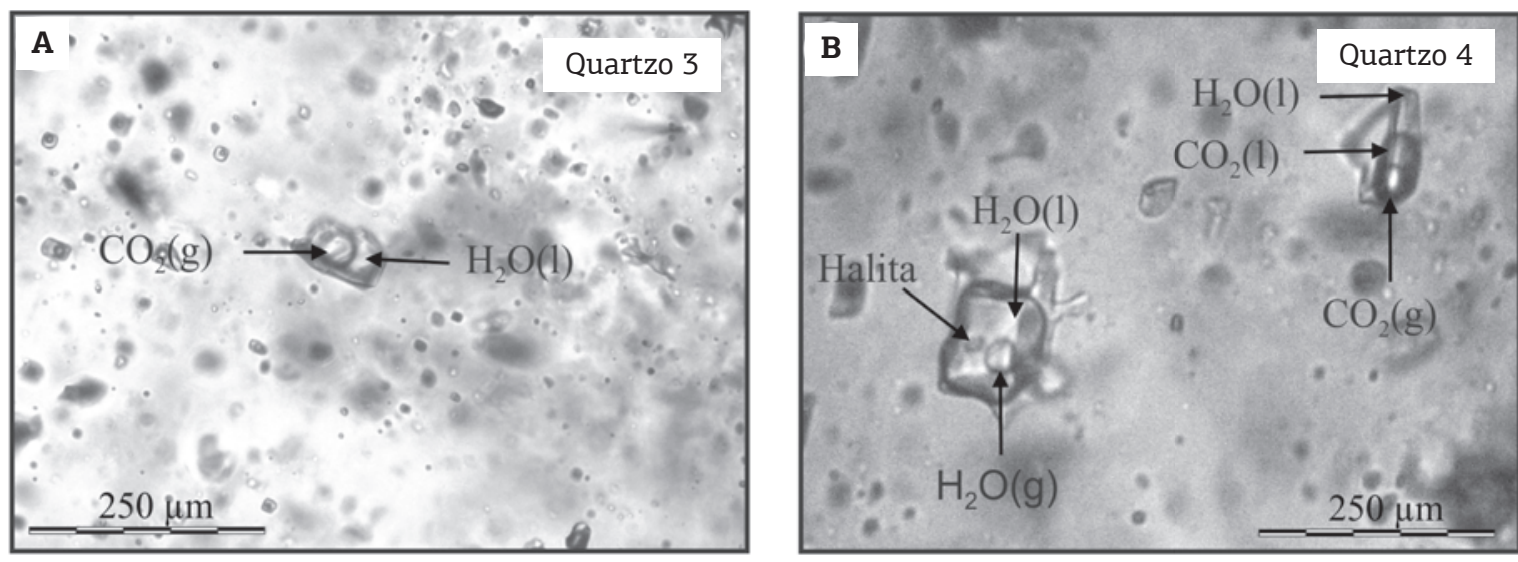

Figura 10. Fotomicrografia de inclusões fluidas aquocarbônicas bifásicas em A e trifásicas em B. 

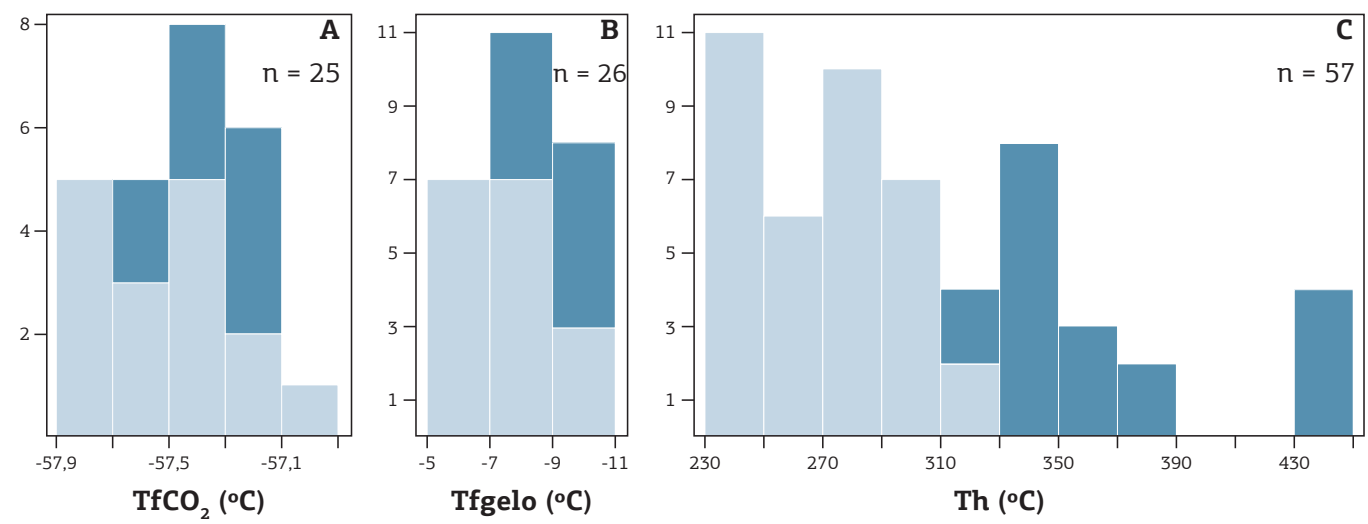

- $\mathrm{H}_{2} \mathrm{O}-\mathrm{CO}_{2}-\mathrm{CaCl}_{2}(\mathrm{Qtz} 4)$

$\mathrm{H}_{2} \mathrm{O}-\mathrm{CO}_{2}-\mathrm{NaCl}(\mathrm{Qtz} 3)$

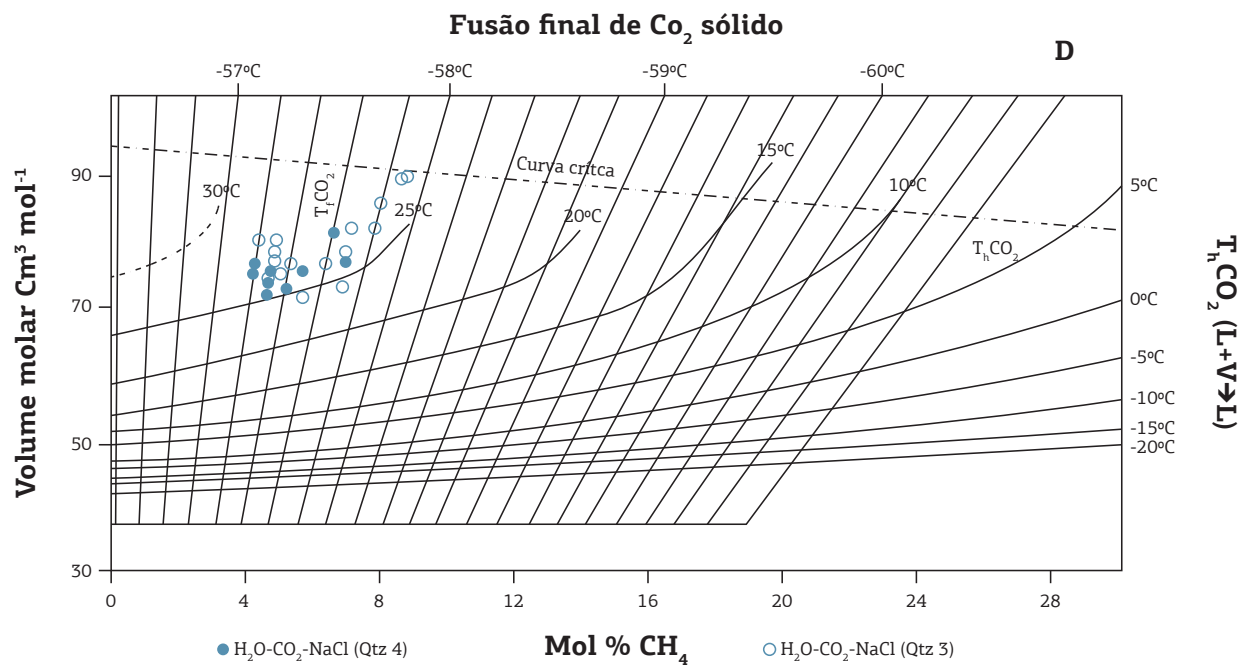

Figura 11. Histograma de frequência da temperatura de fusão do $\mathrm{CO}_{2}-\mathrm{ThCO}_{2}(\mathrm{~A})$, temperatura de fusão do gelo Tfgelo (B) e temperatura de homogeneização total - Th (C) das IF aquocarbônicas em quartzo3 e 4 . Diagrama $\mathrm{TfCO}_{2}$ versus $\mathrm{ThCO}_{2}$ para determinação molar de $\mathrm{CO}_{2}-\mathrm{CH}_{4}$ a partir da $\mathrm{TfCO}_{2}$ e $\mathrm{ThCO}$ para o estado líquido, das IF aquocarbônicas em quartzo3 e 4 (D), modificado de Shepher et al. (1985).

(Fig. 11B). A fusão do clatrato (Tfclat) foi observada em apenas 3 IF aquocarbônicas do quartzo4, com valores de Tfclat entre $-6,1$ e $-8,5^{\circ} \mathrm{C}$, pois a proximidade do índice de refração desse hidrato com o da água dificultou a sua observação. A salinidade das IF aquocarbônicas foi calculada, a partir das Tfclat, pela equação de Bozzo et al. 1973 (apud Parry 1986), com base no sistema $\mathrm{H}_{2} \mathrm{O}-\mathrm{CO}_{2}-\mathrm{NaCl}$, cujos valores obtidos situaram-se entre 19,8 e $20,4 \%$ peso equiv. $\mathrm{NaCl}$. A temperatura de homogeneização total (Th) das IF aquocarbônicas sempre ocorreu para a fase aquosa, com valores de Th entre 230 e 440 oC (Fig. 11C).

\section{GEOTERMÔMETRO DA CLORITA}

Para definir a temperatura e pressão de formação do depósito Ouro Roxo é necessário complementar os dados microtermométicos do fluido mineralizante com um geotermômetro independente. Para tanto foi utilizado o geotermômetro da clorita estabelecido por Cathelineau \& Nieva (1985) e Cathelineau (1988), baseado na proporçáo catiônica do alumínio tetraédrico da clorita $\left(\mathrm{AI}^{\mathrm{IV}}\right)$ que permite calcular sua temperatura de cristalização por meio da equação T=321,98 AlIV-61,92.

Foram realizadas 21 microanálises pontuais, em microssonda eletrônica, nas 4 geraçôes seguintes de clorita hidrotermal reconhecidas no depósito Ouro Roxo: clorita1 (no protólito granitoide), clorita2 (nos milonitos), clorita3 (associada com minério sulfetado nos veios mineralizados) e clorita4 em vênulas tardias (detalhes petrográficos em Veloso, 2011 e Veloso e Santos, 2013). A temperatura de cristalização da clorita é calculada a partir de uma composição anidra, com base em 14 (ou 28) átomos de oxigênios, desprezando-se as 4 moléculas de água da fórmula geral 
$\left(\mathrm{Fe}^{+2}, \mathrm{Mg}, \mathrm{Mn}, \mathrm{Ca}\right)_{6-\mathrm{x}}\left(\mathrm{Al}^{\mathrm{VI}}, \mathrm{Fe}^{+3}\right)_{x}\left(\mathrm{Si}_{4 \times \times} \mathrm{All}^{\mathrm{IV}}{ }_{x}\right) \mathrm{O}_{14} \cdot 4 \mathrm{H}_{2} \mathrm{O}$. Os dados analíticos das cloritas do depósito Ouro Roxo mostraram que suas composições situam-se na transição clinocloro-chamosita, com Al ${ }^{\mathrm{IV}}$ entre 0,97 e 1,41 e a seguinte variação composicional: $\left(\mathrm{Mg}_{0,40-0,66} \mathrm{Fe}_{0,60-0,33}^{+2}\right)_{4,45-4,9}\left(\mathrm{Al}_{0,96-1,0}^{\mathrm{VI}} \mathrm{Fe}_{0,4-0,0}^{+3} \mathrm{Ti}_{0,2-0,0}^{+4}\right)_{1,49-1,1}$ $\left(\mathrm{Si}_{2,59-3,03} \mathrm{Al}^{\mathrm{IV}}{ }_{1,41-0,97}\right) \mathrm{O}_{10}(\mathrm{OH})_{8}$.

As temperaturas obtidas pela equação de Cathelineau (1988) foram também corrigidas com as equaçóes de Kranidiotis \& MacLean (1987) e Zang \& Fyfe (1995), para compensar as variaçōes da fração molar do ferro bivalente que, segundo estes dois últimos autores, influencia na temperatura de cristalizaçáo da clorita. A Tabela 3 exibe as temperaturas de cristalização das cloritas calculadas pelas três equaçôes, sendo as mais elevadas obtidas pela equação de Cathalineau (1988) e as mais baixas pela equação de Zang \& Fyfe (1995). As temperaturas obtidas pela equação de Kranidiotis e MacLean (1987) sáo intermediárias entre aquelas obtidas pelas outras duas equaçóes, porém mais próximas das temperaturas obtidas pela equação de Cathelineau (1988). Em razão dessa discrepância, optou-se pelos valores calculados a partir da equação de Cathelineau (1988).

Tabela 3. Temperaturas de cristalização da clorita hidrotermal do depósito aurífero Ouro Roxo, calculadas com base nas equações de Cathelineau (1988), Kranidiotis \& MacLean (1987) e Zang \& Fyfe (1995), a partir de análises químicas da clorita em microssonda eletrônica

\begin{tabular}{|c|c|c|c|c|c|c|c|c|c|c|c|}
\hline \multirow{2}{*}{\multicolumn{3}{|c|}{$\begin{array}{l}\text { Amostras } \\
\text { AlIV/14(0) }\end{array}$}} & \multirow{3}{*}{$\begin{array}{c}\mathrm{Fe}+2 / \\
(\mathrm{Fe}+2+\mathrm{Mg}) \\
0,33\end{array}$} & \multicolumn{2}{|c|}{ Cathelineau $(1988)^{1}$} & \multicolumn{3}{|c|}{ Kranidiotis \& MacLean $(1987)^{2}$} & \multicolumn{3}{|c|}{ Zang \& Fyfe $(1995)^{3}$} \\
\hline & & & & \multirow{2}{*}{$\begin{array}{c}\mathbf{A l}^{\mathrm{IV}} / \mathbf{1 4}(\mathbf{O}) \\
0,97\end{array}$} & \multirow{2}{*}{$\begin{array}{c}\mathbf{T}\left({ }^{\circ} \mathbf{C}\right) \\
250,40\end{array}$} & \multirow{2}{*}{$\begin{array}{c}\mathbf{A l}^{\mathrm{IV}} / \mathbf{2 8}(\mathbf{0}) \\
1,94\end{array}$} & \multirow{2}{*}{$\begin{array}{c}\mathbf{A l}_{\text {Corr }}^{\mathrm{Iv}} \\
2,17\end{array}$} & \multirow{2}{*}{$\begin{array}{l}\mathrm{T}\left({ }^{\circ} \mathrm{C}\right) \\
248,02\end{array}$} & \multirow{2}{*}{$\begin{array}{c}\mathrm{Al}^{\mathrm{IV}} / \mathbf{2 8}(\mathbf{0}) \\
1,94\end{array}$} & \multirow{2}{*}{$\begin{array}{c}\mathbf{A l}_{\text {Corr }}^{\mathbf{I V}} \\
1,95\end{array}$} & \multirow{2}{*}{$\begin{array}{c}\mathbf{T}\left({ }^{\circ} \mathbf{C}\right) \\
224,59\end{array}$} \\
\hline$\underset{\sigma}{E}$ & $\overrightarrow{0}$ & 1 & & & & & & & & & \\
\hline मี & $\vec{U}$ & 2 & 0,33 & 1,05 & 276,16 & 2,11 & 2,34 & 266,04 & 2,11 & 2,12 & 242,64 \\
\hline \multirow{7}{*}{ 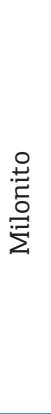 } & \multirow{7}{*}{ 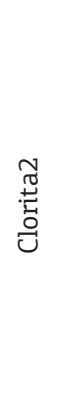 } & 3 & 0,44 & 1,13 & 301,92 & 2,25 & 2,56 & 289,36 & 2,25 & 2,16 & 246,89 \\
\hline & & 4 & 0,43 & 1,19 & 321,24 & 2,38 & 2,68 & 302,08 & 2,38 & 2,30 & 261,76 \\
\hline & & 5 & 0,45 & 1,20 & 324,46 & 2,39 & 2,70 & 304,20 & 2,39 & 2,29 & 260,70 \\
\hline & & 6 & 0,44 & 1,22 & 330,90 & 2,43 & 2,74 & 308,44 & 2,43 & 2,34 & 266,01 \\
\hline & & 7 & 0,43 & 1,22 & 330,90 & 2,44 & 2,74 & 308,44 & 2,44 & 2,36 & 268,13 \\
\hline & & 8 & 0,46 & 1,22 & 330,90 & 2,44 & 2,76 & 310,56 & 2,44 & 2,33 & 264,95 \\
\hline & & 9 & 0,45 & 1,26 & 343,77 & 2,51 & 2,83 & 317,98 & 2,51 & 2,41 & 273,44 \\
\hline \multirow{7}{*}{ 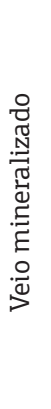 } & \multirow{7}{*}{ 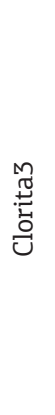 } & 10 & 0,34 & 1,17 & 314,80 & 2,34 & 2,58 & 291,48 & 2,34 & 2,34 & 266,01 \\
\hline & & 11 & 0,37 & 1,26 & 343,77 & 2,52 & 2,78 & 312,68 & 2,52 & 2,49 & 281,94 \\
\hline & & 12 & 0,57 & 1,35 & 372,75 & 2,71 & 3,11 & 347,66 & 2,71 & 2,51 & 284,06 \\
\hline & & 13 & 0,58 & 1,37 & 379,19 & 2,75 & 3,16 & 352,96 & 2,75 & 2,54 & 287,25 \\
\hline & & 14 & 0,57 & 1,38 & 382,41 & 2,76 & 3,16 & 352,96 & 2,76 & 2,56 & 289,37 \\
\hline & & 15 & 0,59 & 1,39 & 385,63 & 2,79 & 3,20 & 357,20 & 2,79 & 2,57 & 290,43 \\
\hline & & 16 & 0,56 & 1,40 & 388,85 & 2,80 & 3,19 & 356,14 & 2,80 & 2,61 & 294,68 \\
\hline \multirow{5}{*}{ 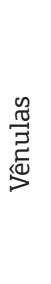 } & \multirow{5}{*}{ 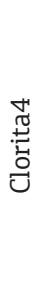 } & 17 & 0,57 & 1,32 & 363,09 & 2,64 & 3,04 & 340,24 & 2,64 & 2,44 & 276,63 \\
\hline & & 18 & 0,59 & 1,33 & 366,31 & 2,66 & 3,07 & 343,42 & 2,66 & 2,44 & 276,63 \\
\hline & & 19 & 0,54 & 1,34 & 369,53 & 2,68 & 3,06 & 342,36 & 2,68 & 2,50 & 283,00 \\
\hline & & 20 & 0,54 & 1,37 & 379,19 & 2,74 & 3,12 & 348,72 & 2,74 & 2,56 & 289,37 \\
\hline & & 21 & 0,60 & 1,38 & 382,41 & 2,76 & 3,18 & 355,08 & 2,76 & 2,53 & 286,19 \\
\hline
\end{tabular}

(1) Equação de Cathelineau (1988): $\mathrm{T}\left({ }^{\circ} \mathrm{C}\right)=321,98 \mathrm{Al}^{\mathrm{IV}}-61,92$. $\mathrm{Al}{ }^{\mathrm{IV}}$ calculado para $14(\mathrm{O})$.

(2) Equação de Kranidiotis \& MacLean $(1987)$ : $\mathrm{T}\left({ }^{\circ} \mathrm{C}\right)=106 \mathrm{Al}^{\mathrm{IV}}{ }^{2}+18 . \mathrm{Al}^{\mathrm{IV}}$ calculado para $28(0)$

$\mathrm{Al}^{\mathrm{IV}} \mathrm{Corr}=\mathrm{Al}^{\mathrm{IV}}+0,7 \mathrm{Fe}^{+2} /\left(\mathrm{Fe}^{+2}+\mathrm{Mg}\right) .{ }^{(3)}$ Equação de Zang \& Fyfe $(1995): \mathrm{T}\left({ }^{\circ} \mathrm{C}\right)=106,2 \mathrm{Al}^{\mathrm{V}}{ }_{\text {Corr }}+17,5$.

$\mathrm{Al}^{\mathrm{IV}}$ calculado para $28(\mathrm{O}), \mathrm{Al}^{\mathrm{IV}}{ }_{\text {corr }}=\mathrm{Al}^{\mathrm{IV}}-0,88 \mathrm{Fe}^{+2} /\left(\mathrm{Fe}^{+2}+\mathrm{Mg}\right)+0,2992$.

$\mathrm{Al}^{\mathrm{IV}}=\mathrm{Al}$ tetraédrico calculado (sem correção). $\mathrm{Al}^{\mathrm{IV}}{ }_{\text {corr }}=\mathrm{Al}$ tetraédrico corrigido 
Os dados analíticos e geotermométricos das cloritas mostram que o processo hidrotermal começou provavelmente no início do cisalhamento, formando clorita 1 (clinocloro), em temperaturas baixas $\left(250\right.$ a $\left.275^{\circ} \mathrm{C}\right)$, com fração molar do $\mathrm{Fe}^{+2}$ igual a 0,33 (Fig.12), que ocorre nos granitoides encaixantes dos corpos mineralizados. Com a progressáo do cisalhamento, começou a formar clorita2 (clinocloro) nos milonitos, em temperaturas entre 300 e $345^{\circ} \mathrm{C}$, com fração molar do $\mathrm{Fe}^{+2}$ entre 0,43 e 0,46 (Fig. 12). No ápice do processo hidrotermal, formaram-se os veios mineralizados juntamente com clorita3 (clinocloro-chamosita), com fração molar do $\mathrm{Fe}^{+2}$ entre 0,34 e 0,59 e temperaturas entre 315 e $388^{\circ} \mathrm{C}$ (Fig. 12) que deve representar o intervalo de temperaturas de formação do minério. No declínio do processo hidrotermal formaram-se vênulas tardias de clorita4 (chamosita), em temperaturas entre 365 e $380^{\circ} \mathrm{C}$, com fração molar do $\mathrm{Fe}^{+2}$ entre 0,54 e 0,60 (Fig. 12), que cortam os corpos mineralizados. A evoluçáo termal e composicional das cloritas durante o processo hidrotermal no depósito Ouro Roxo evidencia um aporte contínuo de ferro reduzido

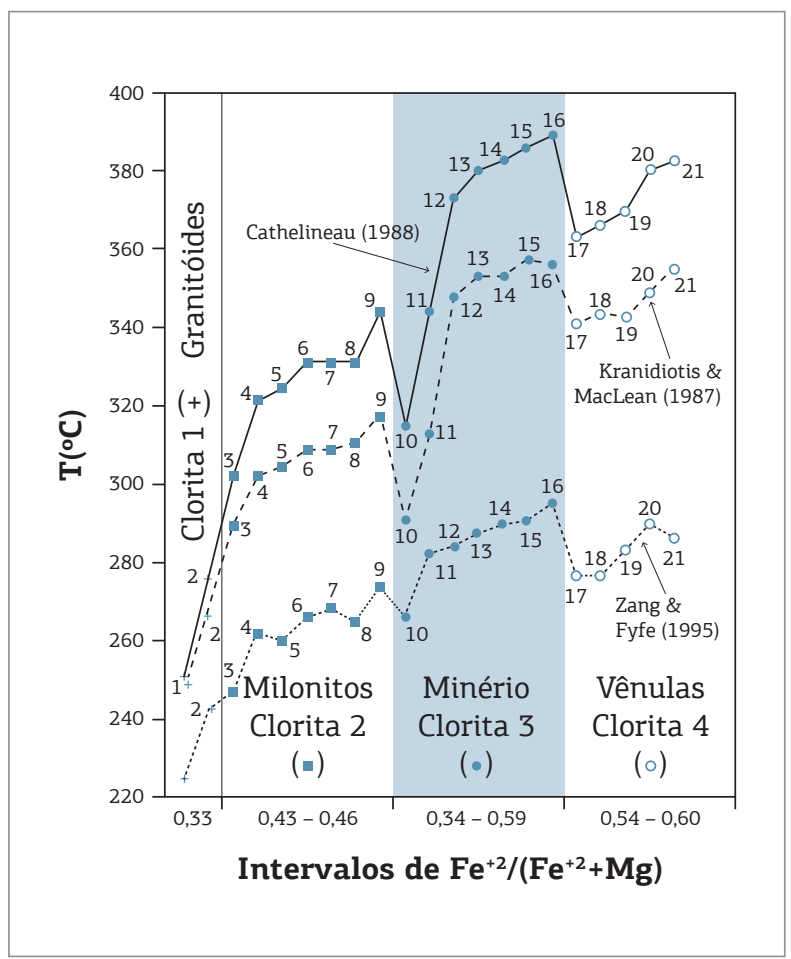

Figura 12. Temperaturas de cristalização das quatro gerações de clorita hidrotermal do depósito aurífero Ouro Roxo, calculadas com base nas equações de Cathelineau (1988), Kranidiotis e MacLean (1987) e Zang e Fyfe (1995), a partir de análises químicas da clorita em microssonda eletrônica, conforme dados da tabela 3. Intervalos da fração molar de $\mathrm{Fe}^{+2}$ no eixo horizontal. no sistema, proveniente da decomposição dos minerais ferromagnesianos do granitóide hospedeiro do minério, que favoreceu a formação de clorita chamosita e pirita juntamente com o minério.

Os valores da pressáo de aprisionamento dos fluidos mineralizantes do depósito Ouro Roxo foram corrigidas a partir das isócoras das inclusóes fluidas e das temperaturas de cristalização das cloritas hidrotermais dos veios mineralizados (Fig. 13). Aplicando-se o intervalo de temperaturas de cristalização da clorita3 $\left(315\right.$ e $\left.388^{\circ} \mathrm{C}\right)$, associada com o minério, no diagrama das isócoras, as linhas de temperatura interceptam as isócoras do fluido aquocarbônico (A4) e das salmoras (S4 e S6) a pressóes mínima e máxima de 2,05 e $4,15 \mathrm{~kb}$ que correspondem, aproximadamente, a profundidades entre 7 e $14 \mathrm{~km}$. As condiçóes de temperatura e pressão (T-P) de formação do depósito Ouro Roxo (área cinza no diagrama da figura 13), situadas no campo de estabilidade da muscovita + clorita e entre os campos da biotita e ilita, indicam condiçóes mesozonais para a formação do depósito, compatível com o domínio dúctil-rúptil caracterizado pela intercalação de milonitos e brechas que hospedam os corpos mineralizados.

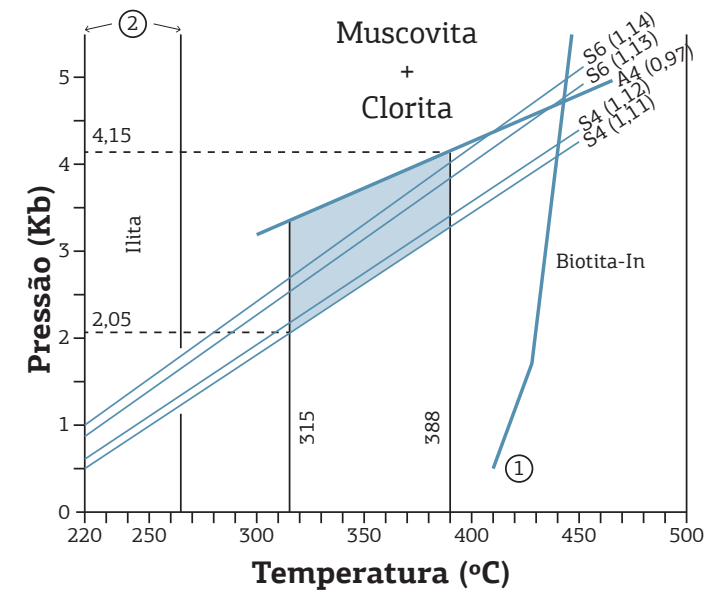

Figura 13. Condições de pressão e temperatura - P-T (área cinza) para a formação do depósito aurífero Ouro Roxo, no campo de estabilidade da muscovita + clorita. As temperaturas de 315 e $388^{\circ} \mathrm{C}$ foram calculadas pelo geotermômetro da clorita. As isócoras S4 e S6 são de salmouras em quartzo 4 e 6 , respectivamente, enquanto que a isócora A4 é de inclusão fluida aquocarbônica em quartzo 4 (entre parênteses, os valores das densidades das inclusões fluidas). Linha 1 segundo Nitsch (1970) e linha 2 segundo Hoffman e Hower (1979). 


\section{DISCUSSÃO}

\section{Origem e evolução do sistema de fluidos}

As características petrográficas e os dados microtermométricos das inclusôes fluidas estudadas mostraram que um fluido aquocarbônico de média salinidade e dois fluidos aquosos, um do sistema $\mathrm{H}_{2} \mathrm{O}-\mathrm{NaCl}-\mathrm{MgCl}_{2}-\mathrm{FeCl}_{2}$ de baixa a média salinidade e outro do sistema $\mathrm{H}_{2} \mathrm{O}-\mathrm{NaCl}-\mathrm{CaCl}_{2}$ (saturado e não saturado), compóem o sistema de fluidos do depósito aurífero Ouro Roxo.

As características semelhantes das inclusôes fluidas aquocarbônicas em quartzos3 e 4, com mesma composição e pequena variação de F, evidenciam tratar-se do mesmo fluido, possivelmente homogêneo quando aprisionado (Ramboz et al. 1982). O conteúdo de $\mathrm{CO}_{2}$ nas IF aquocarbônicas (até 40\% de $\mathrm{CO}_{2}$ ) pode ser explicado pelas reaçóes de hidrólise durante a alteração hidrotermal da rocha hospedeira (alteraçóes propilítica e fílica) que consumiram água do fluido mineralizante, enriquecendo-o em $\mathrm{CO}_{2}$. $\mathrm{O}$ caráter primário das IF e a associação do minério com o quartzo4 evidenciam a contemporaneidade do fluido aquocarbônico com estas duas geraçóes de quartzo hidrotermal e com o minério. $\mathrm{O}$ controle estrutural dos corpos de minério pela zona de cisalhamento evidencia também uma contemporaneidade entre zona de cisalhamento, o minério e o fluido aquocarbônico, características que permitem considerá-lo como possível fluido mineralizante. As IF do quartzo3 podem representar amostras do fluido em condiçóes mais rúpteis (menor profundidade) do que as IF em quartzo4, como maior Th (330 a $440^{\circ} \mathrm{C}$ ), provavelmente captadas em condiçóes mais dúcteis (maior profudidade). Entretanto a relação genética entre a zona de cisalhamento e o fluido aquocarbônico é duvidosa. A salinidade do fluido aquocarbônico do depósito Ouro Roxo (19 a $20 \%$ peso equiv. $\mathrm{NaCl}$ ) é muito elevada quando comparada aos depósitos auríferos tipo lode orogênico, tipicamente relacionados à zonas de cisalhamento (Groves et al. 1998, Goldfarb et al. 2001, 2005). Além disso, os fluidos aquocarbônicos de origem metamórfica dos depósitos orogênicos são normalmente mais enriquecidos em $\mathrm{CH}_{4}$ e $\mathrm{N}_{2}$.

Quanto aos fluidos aquosos, é possível diferenciá-los, no diagrama Te versus salinidade (Fig. 14A), em dois sistemas químicos: 1) fluido $\mathrm{H}_{2} \mathrm{O}-\mathrm{NaCl}-\mathrm{MgCl}_{2}-\mathrm{FeCl}_{2}$ em cristais de quartzo3, com Te entre $-34,8$ e $-42,8^{\circ} \mathrm{C}$ e salinidade média; 2) fluido $\mathrm{H}_{2} \mathrm{O}-\mathrm{NaCl}-\mathrm{CaCl}_{2}$ em cristais de quartzo 4 e 6, com Te entre -58 e $-66,4^{\circ} \mathrm{C}$. Tanto IF não saturadas, com salinidade média, como IF saturadas ocorrem nesse sistema. No fluido saturado, a temperatura de dissolução da halita (TDH), nas duas geraçôes de quartzo, é menor que a temperatura de homogeneização (Th), o que pode caracterizar o aprisionamento do fluido como homogêneo (Fig. 14B).

Por outro lado, a ocorrência de dois fluidos primários (aquocarbônico e aquoso) nos cristais de quartzo3 e 4 é compatível com um aprisionamento heterogêneo dos dois fluidos.
No diagrama Th versus salinidade (Fig. 14B), observa-se que as IF não saturadas do sistema $\mathrm{H}_{2} \mathrm{O}-\mathrm{NaCl}-\mathrm{MgCl}_{2}-\mathrm{FeCl}_{2}$, em quartzo3, apresentam uma variação na salinidade (6 a $18 \% \%$ peso $\mathrm{NaCl}$ eq.) que pode ser explicada por meio de possível mistura com fluidos de salinidade diferente, mas de temperatura similar. A distribuição das IF aquosas do sistema $\mathrm{H}_{2} \mathrm{O}-\mathrm{NaCl}-\mathrm{CaCl}_{2}$, em quartzo4 e 6 , formando um alinhamento diagonal no diagrama da Figura 14B, evidencia uma possível diluição provavelmente causada por mistura com fluido mais frio e de menor salinidade presente no quartzo6. A distribuição vertical na distribuição dos pontos do quartzo6 (Fig. 14B) indica, provavelmente, que as inclusōes foram afetadas por processo de estrangulamento, invalidando, portanto, qualquer interpretação a partir das medidas nessas inclusôes.

As significativas diferenças nas propriedades PVTX dos fluidos aquosos, reconhecidos nos veios mineralizados do depósito Ouro Roxo, demonstram tratar-se de dois fluidos distintos, conforme observado no diagrama da Fig. 14B. O fluido do sistema $\mathrm{H}_{2} \mathrm{O}-\mathrm{NaCl}-\mathrm{MgCl}_{2} \mathrm{FeCl}_{2}$, que ocorre em quartzo3, com salinidade variável, é de origem controversa, podendo ter sido exsolvido do fluido aquocarbônico original por imiscibilidade, mas os poucos dados das inclusóes aquocarbônicas em quartzo3 dificultam essa interpretação. As características das IF aquosas do sistema $\mathrm{H}_{2} \mathrm{O}-$ $\mathrm{NaCl}-\mathrm{CaCl}_{2}$, que ocorrem em quartzo 4 e 6 , indicam tratar-se de um único fluido, o qual passou por diluição. As salmouras foram interpretadas como de origem magmática, relacionadas à fase residual de um magmatismo granítico, aproximadamente contemporâneo à zona de cisalhamento. A ocorrência das salmouras juntamente com fluido aquocarbônico, ambos como IF primárias em cristais de quartzo4, pode ser interpretada pelo menos de duas maneiras. Primeiro, mistura dos dois fluidos, provocando diluição das salmouras e aumento da salinidade do fluido aquocarbônico. Essa mistura de fluidos pode ter ocorrido à época de cristalização do quartzo4, e as salmouras continuaram sua atividade durante a cristalização do quartzo6, em menor temperatura, quando o fluido aquocarbônico não estava mais em atividade, conforme indicado no diagrama da Fig. 15. A segunda possibilidade seria uma aprisionamento heterogênio de um fluido magmático originalmente composto por $\mathrm{H}_{2} \mathrm{O}+\mathrm{CO}_{2}+\mathrm{NaCl}$. Segundo Baker (2002) e Lang \& Baker (2001), a perda de água por evaporação do fluido magmátco pode provocar imiscibilidade entre a fase aquosa salina e a fase carbônica, resultando em salmoura e fluido aquocarônico aprisionados de modo heterogêneo. Esse mecanismo poderia explicar a associaçáo íntima entre fluido aquocarbônico de salinidade média e salmoura em cristais de quartzo 4 no depósito Ouro Roxo. O caráter primário das IF das salmouras em cristais de quartzo4, juntamente com o fluido aquocarbônico e com o minério, permite considerar também as salmouras como possível fluido mineralizante. $\mathrm{O}$ granito Maloquinha, de idade 1,88 a 1,87Ga, que ocorre na área do depósito Ouro Roxo, parece ser um bom candidato para a fonte das salmouras. 
Salinidade (\% peso equiv. $\mathrm{NaCl}$ )
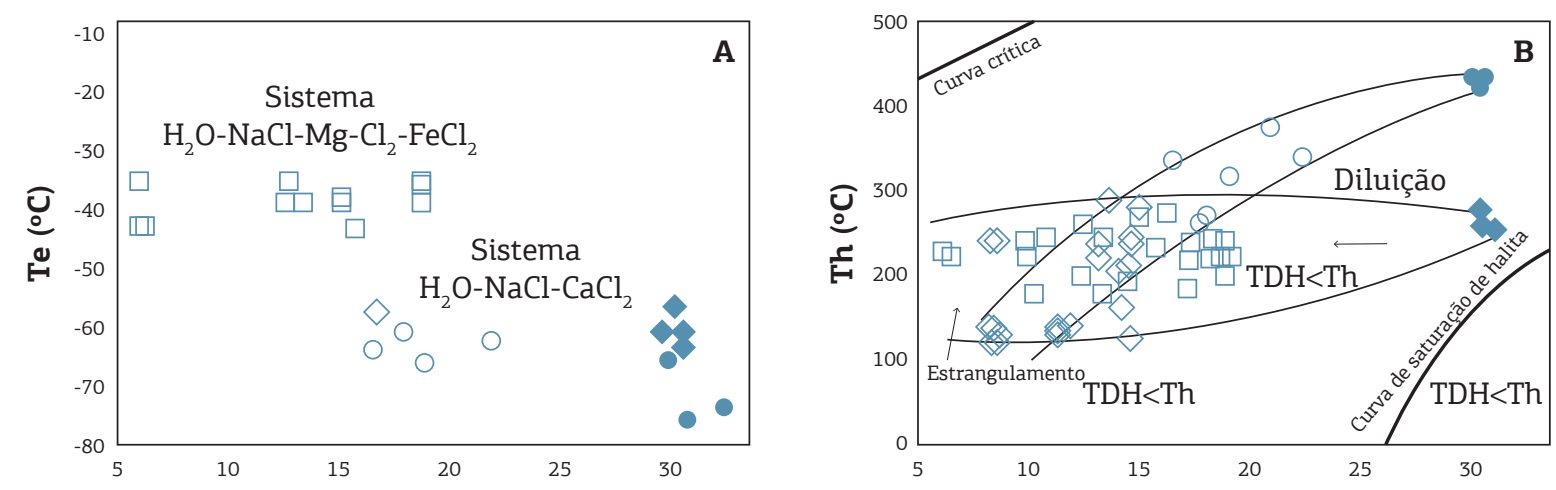

$\square \mathrm{H}_{2} \mathrm{O}-\mathrm{NaCl}-\mathrm{Mg}-\mathrm{Cl}_{2}-\mathrm{FeCl}_{2}(\mathrm{Qtz} 3)$

$$
\begin{aligned}
& \mathrm{H}_{2} \mathrm{O}-\mathrm{NaCl}-\mathrm{CaCl}_{2}(\mathrm{Qtz} 4) \\
& \text { (saturada) }
\end{aligned}
$$$$
\diamond \mathrm{H}_{2} \mathrm{O}-\mathrm{NaCl}-\mathrm{CaCl}_{2}(\mathrm{Qtz} 6)
$$

$\rightarrow$ (saturada)

Figura 14. Diagramas do ponto eutético Te (A) e da temperatura de homogeneização Th (B) versus salinidade dos fluidos aquosos, em quartzo3, 4 e 6, no sistema Ouro Roxo em (A) e mostrando dois sistemas com base no Te e variação da salinidade desde fluidos não saturados até saturados. A variação de salinidade dos fluidos no quartzo 3, a diluição dos fluidos nos quartzos 4 e 6 e o estrangulamento nas inclusões do quartzo 6 em (B).

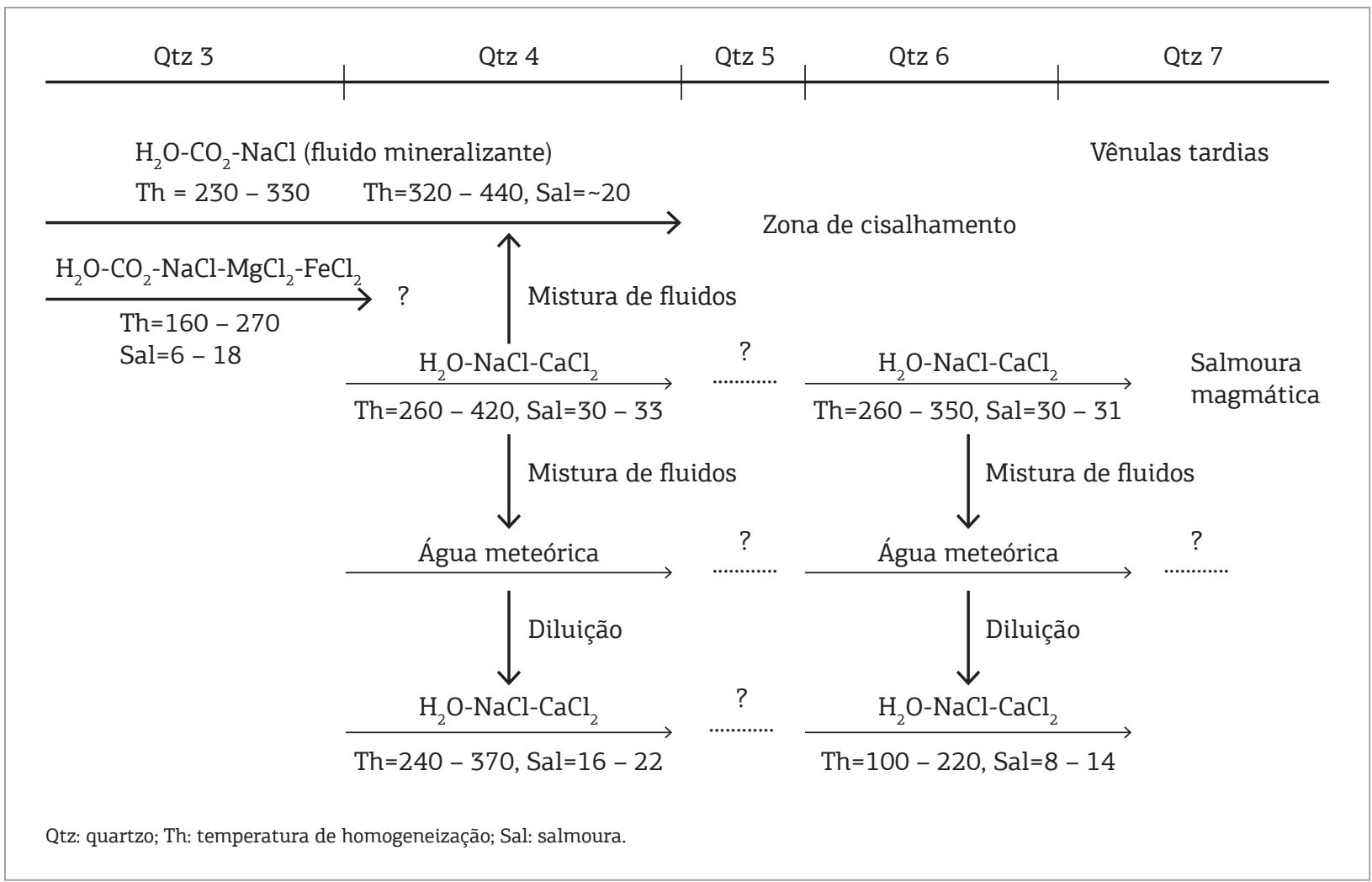

Figura 15. Evolução do sistema de fluidos do depósito Ouro Roxo, mostrando os fluidos mineralizantes (aquocarbônico e salmouras magmáticas) e os processos de mistura e diluição que afetaram os fluidos do sistema Ouro Roxo. 
Água menos salina, provavelmente meteórica, deve ter infiltrado no sistema hidrotermal à época de cristalização do quartzo6, posteriormente à formação do depósito, quando o mesmo já se encontrava mais próximo da superfície, e se misturou com as salmouras que sofreram nova diluição, provocando, por outro lado, aumento da salinidade da água meteórica, como demonstram as inclusóes aquosas secundárias de baixa salinidade do sistema $\mathrm{H}_{2} \mathrm{O}-\mathrm{NaCl}-\mathrm{CaCl}_{2}$, presentes no quartzo6 (Fig. 15). A evolução dos fluidos nas respectivas geraçôes de quartzo do depósito Ouro Roxo pode ser visualizada no gráfico da Fig. 15.

\section{Mecanismo de transporte e deposição do ouro}

A solubilidade dos metais nas soluções hidrotermais é sensivelmente afetada pela variação da fugacidade de oxigênio e do enxofre (fO2 e fS2) e pH, atribuindo ao estado redox dos fluidos grande importância no controle do transporte e deposiçáo dos metais.

A paragênese sulfetada da mineralizaçáo do depósito Ouro Roxo, a ausência de óxidos hidrotermais e a presença de outros gases, principalmente metano (entre 4 e $9 \mathrm{~mol} \%$ ) no fluido aquocarbônico (Fig. 11D), demonstram a natureza redutora do fluido mineralizante, indicando que o enxofre presente nas soluçôes se encontrava, em grande parte, na forma reduzida $\left(\mathrm{H}_{2} \mathrm{~S}\right.$ ou $\mathrm{HS}^{-}$). Os trabalhos experimentais têm demonstrado que, nessas condiçôes, os complexos de enxofre reduzido, como os tiocomplexos $\mathrm{AuHS}^{-2}$ e/ou $\mathrm{HAu}(\mathrm{HS})_{2}^{\circ}$, sáo os principais ligantes durante o transporte do ouro. A predominância de mica branca na paragênese hidrotermal indica que o $\mathrm{pH}$ dos fluidos mineralizantes tornou-se neutro a levemente alcalino (Romberger 1988, 1990). Esses dados indicam que o fluido mineralizante do depósito Ouro Roxo pode ser caracterizado como uma solução aquosa predominantemente redutora, rica em $\mathrm{CO}_{2}$, neutra a levemente alcalina e $\mathrm{T}=315-388^{\circ} \mathrm{C}$. Por outro lado, as condiçôes mais oxidantes e ácidas registradas nas salmouras do sistema $\mathrm{H}_{2} \mathrm{O}-\mathrm{NaCl}_{-} \mathrm{CaCl}_{2}$ (isócoras S4 e S6, Fig. 13) devem ter favorecido a atividade do cloro, tendendo a formar complexos clorados. No entanto, os trabalhos experimentais de Henley (1973) demonstraram que os complexos clorados são eficientes no transporte do ouro somente em temperaturas superiores a $400^{\circ} \mathrm{C}$. As temperaturas abaixo de $400^{\circ} \mathrm{C}$ registradas na clorita do depósito Ouro Roxo limitam a atuaçáo dos complexos clorados nesse depósito para o transporte do ouro. Entretanto, os clomplexos clorados podem ter sido importantes no transporte dos outros metais do minério (Cu e Bi) pelas salmouras.

A precipitação do ouro acorre quando a solubilidade dos complexos é diminuída até a sua desestabilização. Processos que podem atuar nos sistemas hidrotermais e afetar os parâmetros físico-químicos dos fluidos mineralizantes e consequentemente provocar a deposição do ouro são: resfriamento dos fluidos (Norton \& Cathles 1979), interaçâo fluido-rocha (Groves \&
Phillips 1987), imiscibilidade de fluidos (Sibson et al. 1988) e mistura de fluidos (Nesbitt \& Muehlenbachs 1989). As principais mudanças nos parâmetros físico-químicos dos tiocomplexos $\mathrm{Au}(\mathrm{HS})_{2}{ }_{2}^{-} \mathrm{e} \mathrm{HAu}(\mathrm{HS})_{2}{ }^{\circ}$, provocadas pelos processos anteriormente citados, são aumento da $\mathrm{fO}_{2}$ e diminuição da $\mathrm{fS}_{2}$ e do $\mathrm{pH}$.

Os dados petrográficos e de inclusôes fluidas do depósito Ouro Roxo evidenciam que a interação fluido-rocha com reaçôes de hidrólise e sulfetação e a mistura de fluidos aquocarbônico e salmouras magmáticas (ou imiscibilidade entre estes fluidos) foram os principais mecanismos responsáveis pela desestabilização dos complexos auríferos e, consequentemente, pela deposiçáa do ouro. A interaçáo entre os fluidos e os feldspatos e minerais ferromagnesianos do granitóide hospedeiro, resultou em reaçôes de hidrólise, com alteração filica e propilítica, associadas com sulfetação, que provocaram redução de $\mathrm{fO}_{2}$ e $\mathrm{fS}_{2}$. Por outro lado, a mistura (ou imiscibilidade) entre os fluidos aquocarbônicos e as salmouras $\left(\mathrm{H}_{2} \mathrm{O}\right.$ $\mathrm{NaCl}-\mathrm{CaCl}_{2}$ ), observada em quartzo4, provocou aumento de $\mathrm{fO}_{2}$ e diminuiçáo de $\mathrm{pH}$. O aumento da $\mathrm{fO}_{2}$ e reduçáo conjunta de $\mathrm{fS}_{2}$, provocada pela alteraçáo hidrotermal, associada com diminuiçáo de $\mathrm{pH}$, provocada pela mistura dos fluidos, favoreceram a deposição do ouro, juntamente com os sulfetos de ferro, em sítios de transtensão da zona de cisalhamento.

\section{CONCLUSÕES E MODELO GENÉTICO}

Os dados geológicos apresentados sobre o depósito aurífero Ouro Roxo e suas rochas hospediras indicam que os granitoides da Suíte Intrusiva Tropas foram afetados pela zona de cisalhamento Ouro Roxo-Canta Galo, mas não tiveram participação na gênese do depósito Ouro Roxo. Esta relação entre os granitóides hospedeiros e os corpos mineralizados encontra respaldo nos dados geocronológicos de Frantz et al. (2005) que obtiveram idades de 1900 e 1880 Ma para a cristalização dos granitóides hospedeiros (Suíte Tropas) e para o hidrotermalismo respectivamente, e também nos dados de Veloso (2011) e Veloso \& Santos (2013) que obtiveram uma idade $\mathrm{Pb}-\mathrm{Pb}$ de $1858 \mathrm{Ma}$ para a formaçāo do minério Ouro Roxo. Considerando que o hidrotermalismo deve ter sido contemporâneo ao cisalhamento, este deve ter ocorrido em torno de 20 a $40 \mathrm{Ma}$ após a cristalizaçấo dos granitóides Tropas, aproximadamente na época do magmatismo Maloquinha.

Os dados de inclusões fluidas indicam que os prováveis fluidos mineralizantes são fluido aquocarbônico e salmouras magmáticas que ocorrem associados com o minério em cristais de quartzo4 $\mathrm{em}$ veios e charutos controlados pelo cisalhamento. Não há uma conclusão inequívoca para a origem do fluido aquocarbônico. Ele pode ser um fluido náo magmático captado pelo cisalhamento que se misturou com as salmouras durante a atuação do cisalhamento e formaçáo do depósito aurífero. Por outro lado, a ausência de metamorfismo regional 
contemporâneo ao depósito Ouro Roxo e a salinidade média (19 a 20\%peso eq. $\mathrm{NaCl}$ ) do fluido aquocarbônico não favorece uma origem metamórfica para este fluido. Estas características do fluido aquocarbônico e sua associação com salmouras magmáticas sugerem que estes dois fluidos podem ter uma origem magmática comum, com posterior separação por imiscibilidade. Dados de isótopos estáveis $\left(\delta^{18} \mathrm{O}, \delta \mathrm{D}\right.$ e $\left.\delta^{34} \mathrm{~S}\right)$ são necessários para uma melhor definição da origem do fluido aquocarbônico.

A fonte dos metais ( $\mathrm{Au}, \mathrm{Cu}$ e $\mathrm{Bi}$ ) é duvidosa, podendo eles provir da regiáo entre o manto superior e crosta inferior, captados pela zona de cisalhamento, por meio do fluido aquocarbônico, e depositados em sítios de transtensão da zona de cisalhamento. Outra alternativa seria o cobre e bismuto provir de magma granítico residual e terem sido transportados por salmouras que, ao se misturarem com o fluido aquocarbônico aurífero, desestabilizaram os complexos metálicos, provocando deposiçáo do minério $(\mathrm{Au}+\mathrm{Cu}+\mathrm{Bi})$, ou ainda os três metais provir do fluido hidrotermal magmático que ao se separar em dois fluidos por imiscibilidade (aquocarbônico e salmoura aquosa) favoreceu a deposição do minério.

O ambiente orogênico de arco magmático, o estilo filoniano do depósito, o controle estrutural pela zona de cisalhamento, a alteração hidrotermal (propilítica + fílica + carbonatização), a associação metálica $(\mathrm{Au}+\mathrm{Cu}+\mathrm{Bi})$, o fluido mineralizante (aquocarbônico de média salinidade e salmouras magmáticas) são compatíveis com um modelo genético com participação tanto do magmatismo granítico (possivelmente o Granito Maloquinha), como fonte de calor, fluidos e metais, como também do cisalhamento, como condicionador de circulação de fluidos e deposição de metais. A maior ou menor participaçáo destes dois processos na gênese do depósito Ouro Roxo depende da origem do fluido aquocarbônico, ainda indefinida. As duas possibilidade mensionadas para a origem desse fluido resulta em duas variantes no modelo genético para o depósito Ouro Roxo. 1) fluido aquocarbônico não magmático captado pela zona de cisalhamento: modelo híbrido entre o modelo orogênico de Groves et al. (1988) e o intrusion-related gold deposits de Sillitoe (1991). 2) fluido aquocarbônico magmático: modelo intrusion-related gold deposits com importante controle estrutural. Outra possibilidade seria o modelo porfirítico, mas a profundidade mesozonal, ausência de fases magmáticas porfirítcas, o estilo filoneano controlado estruturalmente e a alteraçáo hidrotermal (fílica + propilítica + carbonataçáo), sem alteração potássica importante, não favorecem esse modelo. Em qualquer das duas alternativas genéticas mensionadas, pode-se destacar os seguintes estágios (Fig. 16) na evolução do depósito Ouro Roxo: 1) cristalização

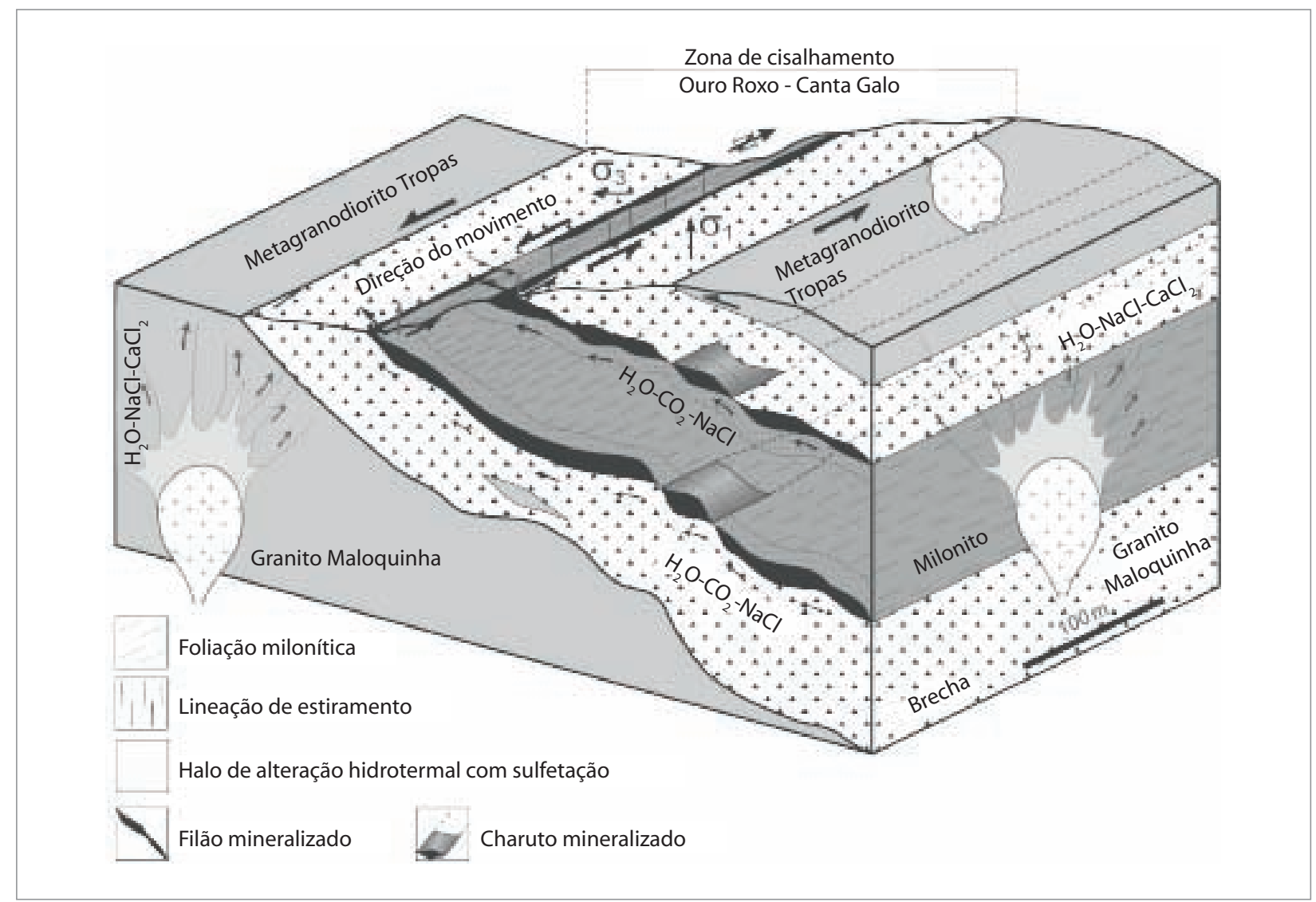

Figura 16. Bloco diagrama esquemático mostrando o controle estrutural dos filões e charutos, em zonas de transtensão da zona de cisalhamento Ouro Roxo-Canta Galo (ZCOC), bem como a participação de fluidos graníticos advindos do Granito Maloquinnha, o qual atribui ao depósito Ouro Roxo um modelo de depósito orogênico com participação magmática. 
dos granitoides Tropas em torno de $1900 \mathrm{Ma}$; 2) cisalhamento Ouro Roxo-Canta Galo em torno de $1880 \mathrm{Ma}$, com possivel circulação de fluido aquocarbônico aurífero. Início do processo hidrotermal, com formação de qurtzo2, fengita1, carbonato1 e clorita1 (clinocloro, $\operatorname{com} \mathrm{T}=250-275^{\circ} \mathrm{C}$ ) a partir da alteração dos minerais ferromagnesianos do granitóide Tropas. 3) Cristalização do Granito Maloquinha entre 1880 e 1860 Ma. Progressão do processo hidrotermal, com formação de fengita2 e clorita2 (clinocloro, com $\mathrm{T}=300-345^{\circ} \mathrm{C}$ ) pré-mineralização, em milonitos. 4) Geração de salmouras metalíferas $(\mathrm{Cu}, \mathrm{Bi})$ e fluido aquocarbônico aurífero (?) magmático, que circularam pelas falhas e fraturas do cisalhamento na área do depósito Ouro Roxo. Ápice do processo hidrotermal, com formaçáo de quartzo3, 4 e 5, fengita3, clorita3 (clinocloro-chamosita, com $\mathrm{T}=315-388^{\circ} \mathrm{C}$ ) e carbonato2, contemporâneos com a deposição do minério (pirita2 + calcopirita + Au + bismutinita), entre 1880 e $1860 \mathrm{Ma}$, em veios e charutos em zonas de transtensão do cisalhamento, encaixados em sequência de milonitos e brechas. 5) Declínio do processo hidrotermal com formação de quartzo6 e vênulas tardias pós-mineralização de quartzo7, clorita4 (chamosita, com $\mathrm{T}=365-380^{\circ} \mathrm{C}$, pirita3 e carbonato3 e 6) infiltração de água meteórica que diluiu as salmouras que continuaram a atuar após a formação do minério, quando o sistema hidrotermal do Ouro Roxo posicionou-se em menor profundidade em consequência de denudação da área.

\section{AGRADECIMENTOS}

Ao Instituto de Geociências (IG) da UFPA pelo suporte técnico. Ao CNPq, pela concessão da bolsa de mestrado à primeira autora. À AMERIX Metals Corp. pelo suporte logístico, técnico e financeiro durante os trabalhos de campo, nas pessoas de seu presidente Dr. Laurense Sneed e do chefe do projeto Ouro Roxo, na época, Geólogo Wiverson Souza. Aos pesquisadores do Grupo de Geologia Econômica (GGE) do IG-UFPA, Professores Márcio Santos e Netuno Villas e ao Professor Francisco Javier Rios, pela utilizaçáo do laboratório de microtermometria do CDTN da UFMG. Este artigo é uma contribuição para o INCT de Geociências da Amazônia-GEOCIAM.

\section{REFERÊNCIAS}

Almeida M.E., Brito M.F.L., Ferreira, A.L., Monteiro M.A.S. 2000. Geologia e Recursos Minerais da Folha Mamãe Anã (SB.21-V-D). Estados do Amazonas e Pará. Escala 1:250.000. Nota explicativa. Projeto Especial Província Mineral do Tapajós (PROMIM). Brasília: CPRM.

Bahia R.B.C. \& Quadros M.L.E.S. 2000. Geologia e recursos minerais da Folha Caracol (SB-21-X-C). Estado do Pará. Escala 1:250.000. Nota explicativa. Projeto Especial Província Mineral do Tapajós (PROMIM). Brasília: CPRM

Baker T. 2002. Emplacement depth and carbon dioxide-rich fluid inclusions in intrusion-related gold deposits. Economic Geology (97): 1111-1117.

Bodnar R.J. 1993. Revised equation and table for determining the freezing point depression of $\mathrm{H}_{2} \mathrm{O}-\mathrm{NaCl}$ solutions. Geochimica et Cosmochimica Acta, 57(3):683-684.

Borizenko A.S. 1977. Study of the salt composition of solutions in gas-liquid inclusions in minerals by the cryometric method. Soviet Geology \& Geophysics, 18:11-19.

Brown P.E. \& Lamb W.N. 1989. FLINCOR 1.4: a microcomputer program for the reduction and investigation of fluid inclusion data. Amer. Mineral, 74:1390-1393.

Cathelineau M. \& Nieva D. 1985. A chlorite solid solution geothermometer. The Los Azufres geothermal system (Mexico). Contributions to Mineralogy and Petrology, 91:235-244.

Cathelineau M. 1988. Cation site occupancy in chlorites and illites as a fuction of temperature. Clay Minerals, 23:471-485.

Davis D.W., Lowenstein T.K., Sencer R.J. 1990. Melting behavior of fluid inclusions in laboratory-grown halite critals in the systems $\mathrm{NaCl}-\mathrm{H}_{2} \mathrm{O}, \quad \mathrm{NaCl}-\mathrm{KCl}-\mathrm{H}_{2} \mathrm{O}, \quad \mathrm{NaCl}-\mathrm{MgCl}-\mathrm{H}_{2} \mathrm{O}$ and $\mathrm{NaCl}-\mathrm{CaCl}_{2}-\mathrm{H}_{2} \mathrm{O}$. Geochimica et Cosmochimica Acta, 54:591-601.
Ferreira A.L., Almeida M.E., Brito M.F.L., Monteiro M.A.S. 2000. Geologia e recursos minerais da Folha Jacareacanga (SB.21-Y-B), Estados do Amazonas e Pará. Escala 1: 250.000. Nota explicativa, Projeto Especial Província Mineral do Tapajós. Manaus, PROMIM Tapajós/CPRM. 1 CD-ROM.

Goldfarb R.J., Groves D.I., Gardoll S. 2001. Orogenic gold and geologic time: a global synthesis. Ore Geology Reviews, 18:1-75.

Goldfarb R.J., Baker T., Dubé B., Groves D.I., Hart C.J.R., Gosselin P. 2005. Distribution, character, and genesis of gold deposits in metamorphic terranes. Economic Geology and the bulletin of the Society of Economic Geologists, One hundredth anniversary volume 1905-2005:407-450

Groves D.I. \& Phillips G. N. 1987. The genesis and tectonic control on Archean gold deposits of the Western Australian Shield - a metamorphic replacement model. Ore Geology Reviews, 2:287-322.

Groves D.I., Goldfarb R.J., Gebre-Marian M., Hagemann S.G., Robert F. 1998. Orogenic gold deposits: a proposed classification in the context of their crustal distribution and relationship to other gold deposit types. Ore Geology Reviews, 13:7-27.

Henley R.W. 1973. Solubility of gold in hydrothermal chloride solutions. Chemical Geology, 11(2):73-87.

Hoffman J. \& Hower J. 1979. Clay mineral assemblages as low grade metamorphic geothermometers: application to the thrust faulted disturbed belt of Montana, U.S.A. In: Scholle P.A. \& Schluger P.R. (eds.). Aspects of diagenesis. Soc. Econ. Paleont. Mineral, 55-79 (Spec. Publ. 26).

Klein E.L. \& Vasquez M.L. 2000. Geologia e recursos minerais da Folha Vila Riozinho - SB.21-Z-A. Estado do Pará. Escala 1:250.000. Nota explicativa. Projeto Especial Província Mineral do Tapajós. PROMIN Tapajós/CPRM. Brasília: CPRM. 1 CD-ROM.

Kranidiotis P. \& MacLean W.H. 1987. Systematics of chlorite alteration at the Phelps Dodge massive sulfide deposit, Matagami, Québec. Economic Geology, 82(7):1898-1911. 
Lang J.R., Baker T. 2001. Intrusion-related gold systems: the present level of understanding. Mineralium Deposita (36):477-489.

Nesbitt B.E. \& Muehlenbachs K. 1989. Geology, geochemistry, and genesis of mesothermal lode gold deposits of the Canadian Cordillera: evidence for ore formation from envolved meteoric water. In: Keays R.R., Ramsay W.R.H., Groves D.I. (eds.). The geology of gold deposits: the perspective. El Paso, Texas: Society of Economic Geologists, p. 552-563.

Nitsch K.H. 1970. Experimental determination of the upper stability of stilplomelane. Fortschr. Mineral, 47:48-49,

Norton D. \& Cathles L.M. 1979. Thermal aspect of ore deposits. In: Barnes H.L. (ed.). Geochemistry of hydrothermal ore deposits. $2^{\text {nd }}$ ed. New York: Jonh Wiley \& Sons, p. 611-631.

Parry W.T. 1986. Estimation of $\mathrm{XCO}_{2}, \mathrm{P}$ and fluid inclusion volume from fluid inclusion temperature measurements in the system $\mathrm{NaCL}-\mathrm{CO}_{2}-\mathrm{H}_{2} \mathrm{O}$. Economic Geology, 81:1009-1013.

Ramboz C., Pichavant M., Weisbrod A. 1982. Fluid immiscibility in natural process: use and misuse of fluid inclusion data: II. Interpretation of fluid inclusion data in terms of immiscibility. Chemical Geology, 37(1-2):29-48

Romberger S.B. 1988. Geochemistry of gold in hydrothermal deposit U.S. Geological Survey Bulletin 1857, A9-A25.

Romberger S.B. 1990. Transport and deposition of gold in hydrothermal systems. In: Robert F., Sheahan P.A, Gren S.B (eds.). Greenstone gold and crustal evolution. NUNA Conference volume, Val d'Or, 1990. Proceendings..., Montreal, Geological Association of Canada, p. 61-66.

Santos J.O.S., Hartmann L.A., Faria M.S.G., Riker S.R., Souza M.M., Almeida M.E., Mcnaughton N.J. 2006. A compartimentação do Craton Amazonas em províncias: avanços ocorridos no período 2000-2006. In: SBG-NO, Simp. Geol. Amaz., 9., Belém: SBG. CD-ROM.

Shepherd T.J., Rankin A.H., Alderton D.H.M. 1985. A practical guide to fluid inclusions studies. Glasgow: Blackie and Sons.

Sibson R.H., Robert G., Poulsen K.H. 1988. High-angle reverse faults, fluid pressure cycling and mesothermal gold-quartz deposits. Geology, 16:551-555.
Sillitoe, R.H. 1991. Intrusion-related gold deposits. In: Foster R.P. (ed) Gold Metallogeny and Exploration. London, Blackie, p. 165-209.

Souza W.S.P. 2007. I Simpósio Província Aurífera do Tapajós. In: Geologia e Recursos Minerais do Estado de Rondônia. Belém: CPRM. $1 \mathrm{CD}-\mathrm{ROM}$

Sterner S.M., Hall D.L., Bodnar R.J. 1988. Synthetic fluid inclusions: $\mathrm{V}$ - Solubility relations in the $\mathrm{NaCl}-\mathrm{KCl}-\mathrm{H} 2 \mathrm{O}$ system under vapor-saturated conditions. Geochimica et Cosmochimica Acta, 52:989-1005

Vasquez M.L. \& Klein E.L. 2000. Geologia e recursos minerais da Folha Rio Novo - SB.21 - Z- C, Estado do Pará. Escala 1:250.000. Nota explicativa. Projeto Especial Província Mineral do Tapajós. Brasília: CPRM, PROMIM Tapajós. 1 CD-ROM.

Veloso A.S.R. 2011. Geologia e metalogênese do depósito aurífero Ouro Roxo, Província Tapajós, Jacareacanga-PA. MS Dissertation, Instituto de Geociências, Universidade Federal do Pará, Belém, 105 p

Veloso A.S.R. \& Santos M.D. 2013. Geologia, petrografia e geocronologia das rochas do depósito aurífero Ouro Roxo, Província Tapajós, Jacareacanga, PA. Brazilian Journal of Geology, 43:22-36.

Williams-Jones A.E. \& Samson I.M. 1990. Theoretical estimation of halite solubility in the system $\mathrm{NaCl}-\mathrm{CaCl}_{2}-\mathrm{H}_{2} \mathrm{O}$ : applications to fluid inclusions. Canadian Mineralogist, 28:299-34.

Walker R.T \& Samson I.M. 1998. Cryogenic Ramam spectroscopic investigation of fluid inclusion in the system $\mathrm{NaCl}-\mathrm{CaCl} 2-\mathrm{H} 2 \mathrm{O}$ In: Schandt E. (Ed.). 17th General Meeting Int. Toronto, Mineral. Assoc., p. A33.

Zang W. \& Fyfe W.S. 1995. Chloritization of the hydrothermally altered bedrock at the Igarapé Bahia gold deposit, Carajás, Brazil. Mineralium Deposita, 30(1):30-38.

Arquivo digital disponível on-line no site www.sbgeo.org.br 
